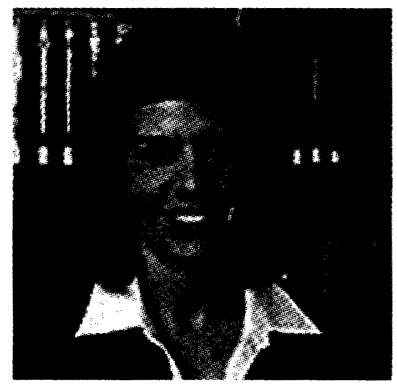

Stacey A. Tovino

Stacey A. Tovino is a Research Professor at the Health Law \& Policy Institute at the University of Houston Law Center and a doctoral student in medical humanities at the Institute for Medical Humanities at the University of Texas Medical Branch. Professor Tovino's research and teaching interests are primarily in the areas of health information privacy; bioethics; research ethics and regulation; literature, medicine, and health law; and the legal history of various aspects of health care in the United States, including midwifery and mental health care. Professor Tovino is the author of several articles, including Incorporating Literature, Literary Nonfiction, and Illness Narratives into a Health Law Curriculum, 9 J. Med. \& Law (forthcoming 2005); American Midwifery Litigation and Legislative Preferences for Physician-Controlled Childbirth, 10 Cardozo Women's L.J. (forthcoming 2005); with William J. Winslade, A Primer on the Law and Ethics of Treatment, Research, and Public Policy in the Context of Severe Traumatic Brain Injury, 14 Annals Health L. 1 (2005); and The Use and Disclosure of Protected Health Information for Research under the HIPAA Privacy Rule, 49 S.D. L. Rev. 447 (2004). Professor Tovino received her law degree from the University of Houston Law Center (1997) and her undergraduate degree from Tulane University (1994). Between 1997 and 2003, Stacey worked as an associate attorney in the Health Industries Group at Vinson \& Elkins in Houston, Texas. 


\title{
HOSPITAL CHAPLAINCY UNDER THE HIPAA PRIVACY RULE: HEALTH CARE OR “JUST VISITING THE SICK”?
}

\author{
Stacey A. Tovino*
}

\section{INTRODUCTION}

Approximately seventy-nine percent of Americans believe that praying can help people recover from illness, injury or disease, ${ }^{1}$ and nearly seventyseven percent of American patients would like spiritual issues discussed as part of their care. ${ }^{2}$ Despite Americans' strong beliefs in the health-related benefits of religious and spiritual practices and traditions, the preamble to the federal Department of Health and Human Services' ("HHS") health information privacy rule (the "Privacy Rule") ${ }^{3}$ explains that health care "does not include

* Research Professor, Health Law \& Policy Institute, University of Houston Law Center, Houston, Texas. Doctoral student, Institute for the Medical Humanities, University of Texas Medical Branch; J.D., 1997, University of Houston Law Center; B.A., 1994, Tulane University. The author is grateful to Harold Y. Vanderpool, Ph.D., Th.M., for his comments on an earlier draft, and Rev. Lerrill White, BCC, for his assistance in understanding the clinical implications of the regulatory interpretations discussed in this Article.

1. Laurel Arthur Burton \& Marcia Sue DeWolf Bosek, When Religion May Be an Ethical Issue, 39 J. RELIGION \& HEALTH 97 (2000) (citing a poll Gallup conducted for CNN/USA Today); see also PROFESSIONAL CHAPLAINCY: ITS ROLE AND IMPORTANCE IN HEALTHCARE 2 (Larry VandeCreek \& Laurel Burton eds., 2001) [hereinafter PROFESSIONAL CHAPLAINCY] (citing Marty Kaplan, Ambushed by Spirituality, TME, June 24, 1996, at 62) (citing similar statistics).

2. Burton \& Bosek, supra note 1, at 97 . For additional statistics describing Americans' beliefs relating to religion, spirituality, and health care, see HAROLD G. KOENIG ET AL., HANDBOOK OF RELIGION AND HEALTH 4 (2001) ("In 1994, 96\% of the population of the United States believed in God or a higher power, $90 \%$ believed in heaven, $79 \%$ believed in miracles, $73 \%$ believed in hell, and $65 \%$ believed in the devil." (citation omitted)); PROFESSIONAL CHAPLAINCY, supra note 1, at 11 (discussing a recent meta-analysis of data from forty-two published mortality studies involving approximately 126,000 participants demonstrating that persons who reported frequent religious involvement were significantly more likely to live longer compared to persons who were involved infrequently); Paul Alexander Clark et al., Addressing Patients' Emotional and Spiritual Needs, 29 JoINT COMMISSION J. QUALITY \& SAFETY 659, 662 (2003) ("79\% of Americans believe that faith aids in recovery, and 56\% believe that faith has helped them recover; $87 \%$ of Americans consider religion to be 'very important' or 'somewhat important' in their life" (internal references and citations omitted)); Jeffrey S. Levin et al., Religion and Spirituality in Medicine: Research and Education, 278 JAMA 792 (1997) ("Recent surveys reveal that nearly $80 \%$ of Americans believe in the power of God or prayer to improve the course of illness and nearly $70 \%$ of physicians report religious inquiries for counseling on terminal illness ... "(footnotes omitted)); Richard P. Sloan et al., Religion, Spirituality, and Medicine, 353 LANCET 664 (1999) ("In a recent poll of 1,000 U.S. adults, $79 \%$ of the respondents believed that spiritual faith can help people recover from disease, and $63 \%$ believed that physicians should talk to patients about spiritual faith" (quoting Tom McNichol, The New Faith in Medicine, USA TODAY, Apr. 7, 1996, at 4.)).

3. HHS published its first, proposed, version of the Privacy Rule on November 3, 1999. See Standards for Privacy of Individually Identifiable Health Information, 64 Fed. Reg. 59,918 (Nov. 3, 1999) [hereinafter the "1999 Proposed Rule"]. After receiving and analyzing com- 
methods of healing that are solely spiritual" (the "preamble"). ${ }^{4}$ The preamble concludes that, "clergy or other religious practitioners that provide solely religious healing services are not health care providers within the meaning of this rule ...."5

Some health care attorneys interpret the preamble as prohibiting hospitals and physicians from sharing individually identifiable health information with hospital-employed chaplains. ${ }^{6}$ On the other hand, many hospital chaplains argue that the preamble fails to distinguish between hospital chaplains (who, as members of the health care team, should be entitled to full access to patients' health information), and community clergypersons (who are entitled to receive limited directory information about those patients who have agreed to disclosures of their directory information). ${ }^{7}$

ments from the public and the health care industry on the 1999 Proposed Rule, HHS adopted what was thought to be a final version of the Privacy Rule on December 28, 2000. See Standards for Privacy of Individually Identifiable Health Information, 65 Fed. Reg. 82,462 (Dec. 28, 2000) [hereinafter the "2000 Final Rule"]. On March 27, 2002, HHS published proposed modifications to the 2000 Final Rule. See Standards for Privacy of Individually Identifiable Health Information, 67 Fed. Reg. 14,776 (Mar. 27, 2002). Finally, on August 14, 2002, HHS adopted final modifications to its 2000 Final Rule. See Standards for Privacy of Individually Identifiable Health Information, 67 Fed. Reg. 53,182 (Aug. 14, 2002) [hereinafter the "2002 Final Modifications"]. The term "Privacy Rule" as used throughout this Article refers to HHS' 2000 Final Rule, as amended by HHS' 2002 Final Modifications, as codified at 45 C.F.R. Parts 160 and 164. at 82,568 .

4. Standards for Privacy of Individually Identifiable Health Information, 65 Fed. Reg.

5. Id.

6. See, e.g., Lerrill White, Pastoral Care Providers are Members of the Healthcare Team in Accordance with the Regulations of the Department of Health \& Human Services, APC NEWS, Jan./Feb.2003, (revised Jan. 2005) ("[S]everal law firms have provided consultation and offered opinions to hospitals and health care systems pertaining to [the Privacy Rule]. These opinions argue that Chaplains or clinically trained pastoral/spiritual care providers are not 'health care providers"'), reprinted in Ass'n of Prof'l Chaplains, Professional Resources, Reading Room: HIPAA and Pastoral Care, at http://www.professionalchaplains.org/ professional-chaplain-services-resources-reading-room-hippa-5.htm (last visited Apr. 21, 2005) (on file with the Indiana Health Law Review); Ira J. Hadnot, Prayers Snared: Churches Fear Red Tape from New Hospital Privacy Rules, Dallas MoRNING News, Jan. 30, 2004, at G1 ("Yet some lawyers have misinterpreted HIPAA and advised hospitals to impose more controls than the law requires, said an official who represents 4,000 chaplains nationwide"). Not all health care attorneys interpret the Privacy Rule as prohibiting hospitals and physicians from sharing individually identifiable health information with hospital-employed chaplains. See, e.g., Letter from R.G. Scott, Attorney at Law, to the Association of Professional Chaplains (May 15, 2003) (on file with author) (arguing that "Hospital staff chaplains are employees . . . of the hospitals where they serve, and they are directly involved in treating patients."); see also Jill C. Robinson, HIPAA: Negotiating the Secular in the Interest of the Sacred, Vermont Ecumenical Council \& Bible Society, at http://www.vecbs.org/statements/hipaa.html (last visited Apr. 21, 2005) (on file with the Indiana Health Law Review) (noting that, "Because it is a federal law, HIPAA has been and will be interpreted by the lawyers representing the interests of each institution directly affected by its mandates ....").

7. See, e.g., Lerrill White \& Rod Pierce, HIPAA Regulations Raise Questions for Chaplains, APC NEws Jan./Feb.2002 (noting that "[w]hat is at stake is the institutional definition of who qualifies as a recognized professional health care provider, thus having access 
This Article provides a context for the controversial preamble within the historical relationship between religion and medicine. Part I of this Article provides relevant background information relating to the Privacy Rule. Part II provides an overview of the historical relationship between religion and medicine, introduces the hospital chaplain and discusses the chaplain's education, certification, and role in the modern American hospital, and addresses the issue whether hospital chaplains are considered part of the health care team. Part III analyzes the preamble and identifies several arguments that may be used to support a hospital chaplain's access to individually identifiable health information. Part IV identifies several approaches for HHS to consider regarding hospital chaplains' access to individually identifiable health information. Part IV also concludes that the preamble, perhaps inadvertently, attempts to relegate religious and spiritual practitioners to the limited role of visiting the sick and identifies an almost exclusive role for the medical establishment in the provision of health care and related social and support services. As such, the preamble is the latest chapter in the continually evolving relationship between American medicine and religion.

\section{INTRODUCTION TO THE HIPAA PRIVACY RULE}

HHS' Privacy Rule, ${ }^{8}$ which implements one section of the Administrative Simplification provisions set forth in the federal Health Insurance Porta-

to appropriate patient information. ... "), reprinted in Ass'n of Prof'l Chaplains, Professional Resources, Reading Room: HIPAA and Pastoral Care, at http://www.professionalchaplains .org/professional-chaplain-services-resources-reading-room-hippa-1.htm (last visited Apr. 21, 2005) (on file with the Indiana Health Law Review); Lerrill White \& Rod Pierce, HIPAA Regulations' Impact on Visitation by Clergy, Lay Ministers and Faith Group Representatives, APC NEws, May/June 2002, reprinted in Ass'n of Prof'l Chaplains, Professional Resources, Reading Room: HIPAA and Pastoral Care, at http://www.professionalchaplains.org/ professional-chaplain-services-resources-reading-room-hippa-2.htm (last visited Apr. 21, 2005) (on file with the Indiana Health Law Review); Lerrill White \& Rod Pierce, Creating HIPAA Compliant Policies and Procedures, APC NEwS July/Aug. 2002 (arguing that hospitals should formally recognize, in written policies and procedures, chaplains and clinical pastoral education students as health care professionals or as providers of patient treatment), reprinted in Ass'n of Prof'l Chaplains, Professional Resources, Reading Room: HIPAA and Pastoral Care, at $\mathrm{http}$ :/www.professionalchaplains.org/professional-chaplain-services-resources-reading-roomhippa-3.htm (last visited Apr. 21, 2005) (on file with the Indiana Health Law Review).

8. Most covered entities were required to comply with the Privacy Rule by April 14, 2003. Small health plans (those health plans with less than five million dollars in annual receipts) had one additional year (i.e., until April 14, 2004) to comply. See 45 C.F.R. § 164.534(b)(2) (2005). Before the general compliance date for the Privacy Rule, state hospital licensing laws and state medical practice acts typically regulated hospitals' and physicians' disclosures of individually identifiable health information. Most state hospital licensing laws and medical practice acts contained provisions that generally prohibited hospitals and physicians from disclosing confidential patient information without the express written authorization of the patient, unless an exception to the general rule applied. See, e.g., TEX. HEALTH \& SAFETY CODE ANN. $\S \S 241.152,241.153$ (Vernon 2004); TEX. OCC. CODE ANN. §§ 159.002 - 159.004 (Vernon 2004). 
bility and Accountability Act of 1996 ("HIPAA"), ${ }^{9}$ regulates both uses and disclosures of protected health information ${ }^{10}$ by certain persons and organizations that fall within the definition of a covered entity.

\section{A. Covered Entities}

Covered entities generally include all health plans, ${ }^{11}$ all health care clearinghouses, ${ }^{12}$ and certain health care providers ${ }^{13}$ (i.e., those health care providers who transmit any health information in electronic form in connection with a standard transaction). ${ }^{14}$ Because most hospitals and physicians electronically transmit health information to health insurers in connection with claims for reimbursement and other standard transactions, most hospitals and physicians will constitute covered entities to which the Privacy Rule applies. Thus, most hospitals and physicians, as well as their employees and workforce members (including hospital chaplains), must ensure that their uses and disclosures of protected health information comply with the Privacy Rule's use and disclosure requirements. ${ }^{15}$

\section{B. Protected Health Information}

The Privacy Rule only regulates a covered entity's (and its employees' and workforce members') use or disclosure of certain information that falls

9. Health Insurance Portability and Accountability Act of 1996, 104 Pub. L. 191, 110 Stat. 1936, 2033 (1996).

10. 45 C.F.R. $\S 160.103$ (2005) (generally defining protected health information as "individually identifiable health information," and excluding from such definition:(i) education records protected by the federal Family Education Rights and Privacy Act ("FERPA"); (ii) certain student treatment records excepted from protection by FERPA; and (iii) employment records held by a covered entity in its role as an employer).

11. Id. (defining a health plan as "an individual or group plan that provides, or pays the cost of, medical care (as defined in section 2792(a)(2) of the PHS Act, 42 U.S.C. $§ 300 \mathrm{gg}$ 91(a)(2))").

12. Id. (defining a health care clearinghouse as an entity that processes health information received from another entity in a nonstandard format into a standard format or receives a standard transaction from another entity and processes health information into nonstandard format for the receiving entity).

13. Id. (defining a health care provider as a "provider of services" under section 1861(u) of the Social Security Act, a "provider of medical or health services" under Section 1861(s) of the Social Security Act, or any other person or organization who furnishes, bills, or is paid for health care in the normal course of business).

14. Id. (defining a covered entity as a health plan, a health care clearinghouse, or a health care provider who transmits any health information in electronic form in connection with a standard transaction). The standard transactions include: (1) claims for reimbursement and patient encounter information; (2) payment for health care services and remittance advice; (3) coordination of benefits; (4) health care claim status; (5) enrollment and disenrollment in a health plan; (6) eligibility for a health plan; (7) health plan premium payments; (8) referral certification and authorization; (9) first report of injury; and (10) health claims attachments. Id.

15. The Privacy Rule's use and disclosure requirements are set forth at 45 C.F.R. $\S \S$ $164.502,164.504,164.506,164.508,164.510,164.512$, and 164.514 (2005). 
within the definition of protected health information ("PHI"). ${ }^{16}$ With a few exceptions, the Privacy Rule generally defines PHI as individually identifiable health information. ${ }^{17}$ Working backwards, the second part of this phrase, health information, is defined as:

\section{[A]ny information, whether oral or recorded in any form or medium, that:}

(1) Is created or received by a health care provider . . . ; and

(2) Relates to the past, present, or future physical or mental health or condition of an individual; the provision of health care to an individual; or the past, present, or future payment for the provision of health care to an individual. ${ }^{18}$

Health information includes not only medical record and billing record information, but also information relating to the provision of health care to an individual. For example, a hospital's list of current inpatients would constitute health information because the list identifies specific individuals to whom the hospital currently is providing health care. ${ }^{19}$

16. 45 C.F.R. $\$ 164.500$ (a) (2005) ("Except as otherwise provided herein, the standards, requirements, and implementation specifications of this subpart apply to covered entities with respect to protected health information." (emphasis added)).

17. 45 C.F.R. $\$ 160.103$ (generally defining protected health information as individually identifiable health information, and excluding from such definition: (i) education records protected by the federal Family Education Rights and Privacy Act ("FERPA"); (ii) certain student treatment records excepted from protection by FERPA; and (iii) employment records held by a covered entity in its role as an employer).

18. 45 C.F.R. $\S 160.103$.

19. In the first-ever criminal conviction for a violation of the Privacy Rule, the United States Attorney's Office interpreted the definition of individually identifiable health information to include demographic information relating to patients of a covered entity, even if such demographic information does not include any specific information about the health of the patient or does not identify the health or medical services provided to the patient. See Plea Agreement at 5, United States v. Gibson, No. CR04-0374RFM (W.D. Wash. Aug. 19, 2004), available at $\mathrm{http}: / /$ world.std.com/ goldberg/hipaacrimesplea.pdf(last visited Apr. 21, 2005) (on file with the Indiana Health Law Review). In October of 2003, defendant Gibson was employed by the Seattle Cancer Care Alliance, a covered health care provider required to comply with the Privacy Rule. Sometime during the month of October, Gibson obtained the name, date of birth, and social security number of a patient who was undergoing treatment for a rare and often fatal form of cancer at the Seattle Cancer Care Alliance. Id. During October and November of 2003, and January of 2004, Gibson inappropriately used and disclosed by telephone the name, date of birth, and social security number of the patient to AT\&T Universal Card, First USA Visa, Chase Manhattan Bank, and Fleet Credit Card Services for purposes of obtaining credit cards in the cancer patient's name. $I d$. Gibson used the credit cards to obtain cash advances and to purchase various items including video games, home improvement supplies, apparel, jewelry, porcelain figures, groceries, and gasoline. Id. The total value of the debt Gibson incurred was $\$ 9,139.42$. Id. On August 18, 2004, the United States Attorney's Office filed a one-count charge in the United States District Court for the Western District of Washington stating that Gibson "knowingly and for a reason other than permitted by [HIPAA] disclosed individually identifiable health information of [a patient], with intent to use that information for personal gain." Id. The following day, Gibson waived his right to be charged by indictment and plead 
Health information must be individually identifiable to constitute PHI. Health information is individually identifiable when: (1) it identifies the individual who is the subject of the information (e.g., because the information includes the patient's name or other direct identifiers); or (2) there is a reasonable basis to believe the information could be used to identify the individual who is the subject of the information. ${ }^{20}$ Although the Privacy Rule does not specifically list those identifiers the inclusion of which would establish a reasonable basis to believe that the information could be used to identify the individual, the Privacy Rule does not apply to information that has been appropriately de-identified. ${ }^{21}$

The Privacy Rule establishes two methods for de-identifying health information. The most popular method, known as the safe harbor method, ${ }^{22}$ provides that a covered entity is considered to have de-identified information if the covered entity removes eighteen enumerated identifiers ${ }^{23}$ from the infor-

guilty. Id. The Plea Agreement indicates that the U.S. Attorney did not require the defendant to have disclosed specific information relating to the patient's past, present, or future physical or mental condition or specific information identifying the types of health care provided to the patient in order to establish a violation of the Privacy Rule. Gibson's inappropriate use and disclosure of "just" the patient's name, date of birth, and social security number was sufficient to establish a violation of the Privacy Rule. See id.

20. 45 C.F.R. $\S 160.103$ (definition of individually identifiable health information).

21. The Privacy Rule's provisions relating to de-identification are set forth at 45 C.F.R. $\S \S 164.502$ (d) and 164.514(a)-(c) (2005).

22. The second method for de-identifying information requires a person with appropriate knowledge of, and experience with, generally accepted statistical and scientific principles and methods for rendering information not individually identifiable to apply such principles and methods and determine that the risk is very small that the information could be used, alone or in combination with other reasonably available information, by an anticipated recipient to identify an individual who is a subject of the information. The person with knowledge of and experience with the statistical and scientific principles must document the methods and the results of his or her analysis that justify the determination that the risk of identification is small. 45 C.F.R. § $164.514($ b)(1)(i), (ii).

23. The following identifiers of the individual (or of relatives, employers, or household members of the individual) must be removed from the information for the information to be deidentified under the safe harbor method: (1) Names; (2) All geographic subdivisions smaller than a State, including street address, city, county, precinct, zip code, and their equivalent geocodes, except for the initial three digits of a zip code if, according to the current publicly available data from the Bureau of the Census: (a) The geographic unit formed by combining all zip codes with the same three initial digits contains more than 20,000 people; and (b) The initial three digits of a zip code for all such geographic units containing 20,000 or fewer people is changed to 000; (3) All elements of dates (except year) for dates directly related to an individual, including birth date, admission date, discharge date, date of death; and all ages over 89 and all elements of dates (including year) indicative of such age, except that such ages and elements may be aggregated into a single category of age 90 or older; (4) Telephone numbers; (5) Fax numbers; (6) Electronic mail addresses; (7) Social security numbers; (8) Medical record numbers; (9) Health plan beneficiary numbers; (10) Account numbers; (11) Certificate/license numbers; (12) Vehicle identifiers and serial numbers, including license plate numbers; (13) Device identifiers and serial numbers; (14) Web Universal Resource Locators (URLs); (15) Internet Protocol (IP) address numbers; (16) Biometric identifiers, including finger and voice prints; (17) Full face photographic images and any comparable images; and (18) Any other unique identifying number, characteristic, or code. 45 C.F.R. $\S 164.514(b)(2)(i)$. 
mation and has no actual knowledge that the remaining information could be used alone or in combination with other information to identify the subject of the information. ${ }^{24}$ Once information has been de-identified, a covered entity may freely use or disclose the information without regulation by the Privacy Rule. However, many covered entities believe that completely de-identifying information renders it essentially useless. ${ }^{25}$

The Privacy Rule generally protects PHI regardless of whether the patient who is the subject of the information is dead or alive. ${ }^{26}$ In addition, the Privacy Rule protects PHI regardless of whether it is written (e.g., a computer generated list of patients or a hand-written progress note), orally spoken (e.g., an ethics committee discussion or a telephone conversation relating to a particular patient), or visibly displayed (e.g., an electronic medical record that is displayed on a computer screen). ${ }^{27}$

This lengthy discussion of PHI is necessary to understand the many ways in which hospital chaplains may access or use PHI. Among numerous other activities, hospital chaplains access or use PHI when they: (1) respond to a physician's order or nurse's referral to provide religious or spiritual care to a particular patient; (2) participate in an ethics committee discussion about a particular patient; (3) access a list of newly admitted inpatients to locate the room number of a particular patient requesting religious or spiritual care; (4) prepare paperwork relating to a patient who has just passed away; (5) coordinate funeral arrangements; (6) refer a patient to a patient advocate, a social worker, or another health care provider for additional social or health services; (8)

24. 45 C.F.R. $\S 164.514(\mathrm{~b})(2)$.

25. See, e.g., Jennifer Kulynych \& David Korn, The New Federal Medical-Privacy Rule, 347 N. ENG. J. MED. 1133, 1134 (2002) (arguing that the Privacy Rule's strict de-identification requirements will complicate hospitals' current practices of releasing information to medical researchers).

26. However, the Privacy Rule does identify a few situations in which PHI about decedents may be used or disclosed without the decedent's (or a personal representative's) prior written authorization. See, e.g., 45 C.F.R. $\$ 164.512(f)(4)$ (2005) (noting that "[a] covered entity may disclose protected health information about an individual who has died to a law enforcement official for the purpose of alerting law enforcement of the death of the individual if the covered entity has a suspicion that such death may have resulted from criminal conduct."); 45 C.F.R. $\$ 164.512(\mathrm{~g})$ (addressing disclosures of PHI relating to decedents by covered entities to coroners, medical examiners, and funeral directors); 45 C.F.R. $\S 164.512$ (i) (addressing disclosures to researchers engaging in research using decedents' information). Other than these limited situations, the Privacy Rule generally protects PHI relating to living and deceased persons equally. See Standards for Privacy of Individually Identifiable Health Information, 65 Fed. Reg. 82,462, 82,632 (Dec. 28, 2000) ("[C]overed entities must under this rule protect the protected health information about a deceased individual in the same manner and to the same extent as required for the protected health information of living individuals.").

27. 45 C.F.R. \& 160.103 (2005) (defining "health information" as "any information, whether oral or recorded in any form or medium . . . "); see also Standards for Privacy of Individually Identifiable Health Information 65 Fed. Reg. 82,462, 82,620 (Dec. 28, 2000) ("Covering oral communications is an important part of keeping individually identifiable health information private. If the final rule were not to cover oral communications, a conversation about a person's protected health information could be shared with anyone."). 
discuss a patient's spiritual needs with another member of the clergy who may be familiar with the patient; and (9) access a patient's record in order to chart the religious or spiritual care services provided to the patient. Hospital chaplains routinely access and use PHI in the course of their job duties.

\section{Uses and Disclosures}

The Privacy Rule regulates both internal uses ${ }^{28}$ of PHI, including uses of PHI by a covered entity's employees and workforce members, as well as external disclosures ${ }^{29}$ of $\mathrm{PHI}$, including disclosures of $\mathrm{PHI}$ by the covered entity to other persons and organizations who are not employees or workforce members of the covered entity. ${ }^{30}$ Although members of the public who commented on HHS' 1999 Proposed Rule recommended that covered entities have fewer requirements for internal uses of PHI than for disclosures, HHS disagreed. $^{31}$

Thus, if a covered hospital wishes to disclose PHI to a community clergyperson who is not employed by the hospital, such as a priest at a local church, the disclosure of PHI by the hospital to the priest must be made in accordance with the use and disclosure requirements set forth in the Privacy Rule, as discussed in Part III.A, below. Likewise, if a hospital-employed chaplain wishes to use PHI maintained by the covered hospital to carry out his or her job duties, the internal use of the information by the employed chaplain also must be made in accordance with the use and disclosure requirements set forth in the Privacy Rule.

28. 45 C.F.R. $\S 160.103$ (defining use to mean, "with respect to individually identifiable health information, the sharing, employment, application, utilization, examination, or analysis of such information within an entity that maintains such information.").

29. Id. (defining disclose to mean "the release, transfer, provision of access to, or divulging in any other manner of information outside the entity holding the information.").

30. The application of the Privacy Rule to both uses and disclosures of health information is different than many state laws, which typically regulate health care providers' disclosures of information to a third party, but not the providers' internal uses of the same information. For example, the Texas Hospital Licensing Law and the Texas Medical Practice Act only regulate disclosures of health information by Texas hospitals and physicians, respectively, but not their internal use of information. TEX. HEALTH \& SAFETY CODE ANN. § 241.152(a) (Vernon 2004) ("Except as authorized by Section 241.153, a hospital or an agent or employee of a hospital may not disclose health care information about a patient to any person . . . without the written authorization of the patient ....") (emphasis added); TEX. OCC. CODE ANN. § 159.002(a),(b) (Vernon 2004) ("A record of the identity, diagnosis, evaluation, or treatment of a patient by a physician that is created or maintained by a physician is confidential and privileged and may not be disclosed except as provided by this chapter") (emphasis added).

31. For example, in the context of research, HHS explained that:

[W]e disagree that an individual's privacy interest is of less concern when covered entities use protected health information for research purposes than when covered entities disclose protected health information for research purposes. Therefore, in the final rule, the research-related requirements . . apply to both uses and disclosures of protected health information ....

Standards for Privacy of Individually Identifiable Health Information, 65 Fed. Reg. at 82,702. 


\section{Religion, MEdicine, AND Hospital ChaplainCY}

Before addressing the issue whether the Privacy Rule permits hospital chaplains to access PHI beyond directory information, this Part II provides an overview of the historical relationship between religion and medicine and discusses the role of the chaplain in the modern American hospital.

\section{A. The Relationship Between Religion and Medicine ${ }^{32}$}

\section{The Western Christian Tradition}

In ancient and medieval times, medicine and religion exhibited a close relationship as evidenced by healing rites, exorcisms, pilgrimages, health cults, ${ }^{33}$ and the fact that many medieval hospitals were conducted by religious orders. $^{34}$ Until well into the Renaissance, spiritual care and medical care frequently were dispensed by the same person, ${ }^{35}$ and priests and physicians often were considered "one and the same." "36 In the Middle Ages, the church was the official body that issued medical licenses to physicians who, typically, were monks or priests, and the church primarily provided care for the poor and the sick. ${ }^{37}$ The hospital of the Middle Ages was a "religious house in which

32. For a detailed discussion of, and timeline relating to, the history of religion, science, and medicine, see KOENIG ET AL., supra note 2, at 24-49.

33. Rodney J. Hunter, Pastoral Care and Healthcare Chaplaincy, in 4 ENCYCLOPEDIA OF BIOETHICS 1975, at 1978 (Stephen G. Post ed., 3rd ed. 2004).

34. Paul Starr, The Social Transformation of AMERICAN MEdicine 149 (1982).

35. See, e.g., William F. MAY, THE PHYSICIAN's COVENANT: IMAGES OF THE HEALER INMEDICALETHICS 26 (1983) (noting that the ancient shaman "often combined three functions: curing the sick, directing communal sacrifice, and escorting the dead to the other world. He combined, in effect, three offices that have been separated in modern times: physician, priest, and undertaker."); Ronald L. Numbers \& Ronald C. Sawyer, Medicine and Christianity in the Modern World, in HEALTH/MEDICINE AND THE FAITH TRADITIONS: AN INQUIRY INTO RELIGION AND MEDICINE 140 (Martin E. Marty \& Kenneth L. Vaux eds., 1982) (noting that "so complimentary were the roles of physician and priest that throughout much of the Middle Ages clerics often provided medical care, even though the ministerial and medical professions were formally distinct."); Sloan et al., supra note 2, at 664 (noting that, "At various times worldwide, medical and spiritual care was dispensed by the same person.").

36. See, e.g., Daniel W. Foster, Religion and Medicine: The Physician's Perspective, in HEALTH/MEDICINE AND THE FAITH TRADITIONS: AN INQUIRY INTO RELIGION AND MEDICINE 245, 250 (Martin E. Marty \& Kenneth L. Vaux eds., 1982) (noting that "For centuries the capacity for healing was considered vested in those with divine power; priest and physician were one and the same."); Sloan et al., supra note 2, at 664; KOENIG ET AL., supra note 2, at 35 (noting that, "[u]ntil well into the Renaissance (the period between the Middle Ages and modern times), the doctor is generally also a priest.").

37. KOENIG ET AL., supra note 2, at 34 (citing Darrel W. Amundsen, The Medieval Catholic Tradition, in CARING AND CURING: HEALTH AND MEDICINE IN THE WESTERN RELIGIOUS TRADITIONS 83(Ronald L. Numbers \& Darrel W. Amundsen eds., 1998)). 
the nursing personnel had united as a vocational community under a religious rule." 38

The eventual segregation of preaching and healing resulted from a variety of factors. ${ }^{39}$ During the Middle Ages, the Roman Catholic Church did not formally forbid the practice of medicine by clergy generally; however, the Church did question the appropriateness of clergypersons engaging in medical practice. ${ }^{40}$ During the late Middle Ages and into the Renaissance, guilds of physicians, surgeons, and apothecaries sought legal monopolies over the healing arts. ${ }^{41}$ When successful, their efforts excluded clergypersons as well as charlatans from practicing medicine. ${ }^{42}$ By the year 1500 , only three of the twenty-three members of the faculty of medicine at Paris were clergypersons. ${ }^{43}$

Despite the efforts of the medical profession and the church to discourage clergypersons from practicing medicine, cleric-physicians persisted in part because the medical guilds had been unable to enforce their monopolies in rural areas "and necessity forced some priests to minister to their flocks." In addition, appropriately credentialed physicians were not always easy to locate and, when they were, their fees sometimes were prohibitive. ${ }^{45}$ Thus, some clergy and other irregular healers continued to practice medicine in small towns and in rural areas into the eighteenth and nineteenth centuries. ${ }^{46}$

Beginning with the Protestant Reformation, Christian ministry began to withdraw its involvement in healing and from making scientific, empirical claims regarding the natural world. ${ }^{47}$ The result was an intellectual and professional division between religion and medicine. ${ }^{48}$ As medicine grew more scientific and ministry became confined to matters of God and the soul, corresponding professional domains were identified. Physicians became responsible for the scientific care of the physical body while members of the clergy became responsible for the spiritual care of the soul. ${ }^{49}$ Medical science began to assign mental and emotional disorders, traditionally considered problems of the soul, to the physical body, and regarded such disorders as potentially treatable by medical means. ${ }^{50}$

38. STARR, supra note 34, at 149 (quoting George Rosen, The Hospital: Historical Sociology of a Community Institution, in THE HOSPITAL INMODERN SOCIETY 10 (Eliot Freidson ed., 1963)).

39. Numbers \& Sawyer, supra note 35 , at 140.

40. Id.

41. Id.

42. Id.

43. Id.

44. Id.

45. Numbers \& Sawyer, supra note 35 , at 140.

46. Id.

47. Hunter, supra note 33, at 1978.

48. Id.

49. Id.

50. Id. 
However, some of the distinctions that had been drawn between the scientific care of the physical body and the spiritual care of the soul began to blur with the development of psychiatry and the religion and health movement in the early twentieth century. ${ }^{51}$ Psychoanalysis and related developments identified psychogenic factors that played a role in many psychiatric disorders, and empirical studies in psychosomatic medicine revealed the important effects of emotional and spiritual attitudes on physical health and healing. ${ }^{52}$ At the same time, theology began to recover biblical "wholistic" conceptions of human personhood, salvation, and the healing potential of religious ministry. ${ }^{53}$

In this theology the welfare of the whole person, physical, mental, and spiritual, was regarded as a profound unity. The result was a gradual closing of the theoretical gap between medicine and religion and the emergence of a more collaborative style of work between physicians and pastoral caregivers. ${ }^{54}$

\section{The American Relationship}

In colonial America (1603-1787), the close relationship between religion and medicine existed as it had in the Middle Ages. Although medicine in seventeenth and eighteenth century America focused on a rational understanding of the human body and the world of nature, "religious perspectives were consciously and regularly viewed as compatible with and at points augmentative of such knowledge."55 For example, self-help and other similar literature addressing medical treatments identified a combination of natural and religious understandings. ${ }^{56}$ Moreover, many members of the clergy served as physicians. ${ }^{57}$ Heinrich Melchior Muhlenberg, one of the founders of American Lutheranism, undertook a healing ministry in colonial America in part because "doctors [were] few and far between." In addition, prospective American ministers frequently studied medicine during their theological instruction in order to provide a better foundation for the provision of medical services in rural or missionary settings. ${ }^{59}$ In the colonial period, "medical theory and therapy could be readily learned," and the average person who used the title

51. Id.

52. Id.

53. Hunter, supra note 33, at 1978.

54. Id.

55. Harold Y. Vanderpool, Medicine and Medical Ethics, in 2 ENCYCLOPEDIA OF THE AMERICAN RELIGIOUS EXPERIENCE 1253, 1254 (Charles H Lippy \& Peter W. Williams eds., 1988).

56. Id.

57. Id. at 1255; see also Numbers \& Sawyer, supra note 35, at 141 ("In colonial New England, Puritan cleric-physicians provided a significant part of the medical services, especially outside Boston and the larger towns.").

58. Numbers \& Sawyer, supra note 35, at 141.

59. Vanderpool, supra note 55, at 1255. 
"Doctor" had read a few books on medicine and served as an apprentice to a practicing physician for several months or more. ${ }^{60}$

During America's first century (1787-1890), secular beliefs increasingly served as the foundation for medical theory and practice. ${ }^{61}$ Regular practitioners, including those who were educated in anatomy, botany, chemistry, and surgery, relied upon natural explanations and therapies in their practices. They also organized themselves into state medical societies, taught their theories in America's new medical schools, and officially opposed irregular practitioners whose various sects and groups were at odds with traditional theory and practice. ${ }^{62}$ In part due to the opposition between regular and irregular practitioners, ${ }^{63}$ individuals who were both ministers and physicians "withdrew from and were partly squeezed out of medical practice" by the early decades of the nineteenth century. ${ }^{64}$

Following the Civil War, some individuals believed that American medicine and religion conflicted at a fundamental level. ${ }^{65}$ The new sciences of geology, evolutionary biology, psychology, and scientific historiography "question[ed] fundamental biblical assumptions regarding human origins and development, the historical and scientific accuracy of the Bible, and traditional views regarding the nature of the human psyche." When diseases were assigned to specific natural causes, religious explanations became "almost superfluous." ${ }^{167}$ For example, the American response to cholera in 1832 and 1849 was largely religious because the cause of the disease was unknown at that time.$^{68}$ However, when the cause of the disease was discovered in 1866 , religious explanations faded away. ${ }^{69}$

Perhaps as a reaction against conventional medical theories, nineteenth century America witnessed the development of several irregular theories of medicine including, but certainly not limited to, the Thomsonians' heatrestoring botanicals, health food campaigns, and hydropathy. ${ }^{70}$ Joseph Smith's

60. Id.

61. Id. at 1257.

62. Id.

63. See, e.g., MAJOR Problems IN THE History of AMERICAN MEDICINE AND PUBlic HEALTH 55 (John Harley Warner \& Janet A. Tighe eds., 2001) (distinguishing "regular bred physicians" or "regulars" from "non-regular" practitioners).

64. Vanderpool, supra note 55, at 1257.

65. Id.

66. Id.

67. Numbers \& Sawyer, supra note 35, at 139.

68. Id. ("as long as cholera remained a mystery, religious persons felt free to regard it as a miracle, 'a scourge, a rod in the hand of God."') (emphasis in original).

69. Id. ("when cholera threatened to return in 1866, Americans devoted their energies to improving sanitation rather than to discussing the theological meaning of the event.").

70. Vanderpool, supra note 55, at 1258. Thomsonians were followers of Samuel Thomson, a botanic healer who decried the regular medical profession as a murderous monopoly. See, e.g., Samuel Thomson, New GuIDE to Health; OR, Botanic Family PhySician (1835). Thomsonianism was the first organized anti-orthodox system of medical belief and practice. MAJOR PROBLEMS IN THE HISTORY OF AMERICAN MEDICINE AND PUBLIC HEALTH, supra note 63 , at 57. 
botanical remedies, his opposition to tea, coffee, alcoholic beverages, and tobacco, and his emphasis on spiritual healing flourished in frontier settlement areas. $^{71}$

Relative to irregular practitioners, the status of regular physicians improved after the reinstatement of several states' medical licensure laws in the 1870 's, the use of anesthesia and antisepsis in the $1880 \mathrm{~s}$, the beginning of clinical and laboratory research in 1890 , the development and use of vaccines, antitoxins, and X-rays in the $1890 \mathrm{~s}$, and the building of more than three thousand new hospitals in the thirty-eight year period from 1872 to $1910 .^{72} \mathrm{By}$ 1890 , American religion and medicine were widely considered to be operating in separate realms, ${ }^{73}$ and physicians eventually "came to control medical care as off limits to the clergy."74

In the second-half of the nineteenth century and the first-half of the twentieth century, American patients continued, however, to choose their physicians based on subjective and personal judgments that allowed for similarities in religion, ethnic group, and socioeconomic background. ${ }^{75}$ For example, Catholic immigrants tended to select Catholic physicians and Jewish immigrants tended to select Jewish physicians. ${ }^{76}$ During this time period, many American patients also chose their hospitals by religious or ethnic sponsorship. ${ }^{77}$ In 1849, New York Catholics founded St. Vincent's Hospital and, a few years later, New York Episcopals founded St. Luke's. ${ }^{78}$ New York Jews established Mt. Sinai Hospital in 1852, and the Catholics opened their second hospital, St. Francis, in $1865 .^{79}$ By 1885 , Catholics had established 154 hospitals throughout the United States, more than the total number of hospitals

71. Vanderpool, supra note 55 , at 1258-59.

72. Id. at $1259-60$.

73. Id. at 1253 .

74. Id. at 1256 (discussing William Douglass' defense of medicine's separate professional status as "prophetic of the way doctors eventually came to control medical care as off limits to the clergy.").

75. DAVID J. ROTHMAN, STRANGERS AT THE BEDSIDE: A History OF How LAW AND BIOETHICS TRANSFORMED MEDICAL DECISION MAKING 111 (2nd ed., Walter de Gruyter 2003) (1991).

76. Id. at 111 ("In an era when major eastern and Midwestern cities were divided into ghetto enclaves, immigrants tended to select their doctors along ethnic and religious lines. Catholics turned to Catholic doctors, Jews to Jewish doctors ....").

77. Id. at 123; see also STARR, supra note 34, at 174 (noting that ethnic and religious hospitals furnished opportunities for internships and residencies that Jewish, Catholic, and black doctors were denied elsewhere and staff appointments so that they could attend patients of theirs needing hospitalization); ROSEMARY STEVENS, IN SiCKNESS AND IN WEALTH: AMERICAN HOSPITALS IN THE TWENTIETH CENTURY 24 (1989) ("Religious, ethnic, and linguistic diversity in the United States made schools and hospitals visible affirmations of the importance of immigrants and religious groups.").

78. Charles E. Rosenberg, The Care of Strangers: The Rise of america's HOSPITAL SYSTEM 109 (1987).

79. Id.; see also STARR, supra note 34, at 153-54 ("In New York City, according to a historian of its Jewish community, Jews' Hospital (later Mt. Sinai) developed within a few years after its founding into 'the most important Jewish organization in the city.'”). 
that existed in the United States in the late $1860 \mathrm{~s}^{80}$ By 1930 , approximately 640 Catholic hospitals were established in the United States, and the Catholic Hospital Association ("CHA") estimated that one Catholic hospital bed was available for every 231.2 American Catholics. ${ }^{81}$ Social and medical historians emphasize the regularity with which members of religious communities built and frequented their own hospitals during the early part of the twentieth century:

In New York City from 1925 to 1945,60 percent of the fifty-eight general hospitals had religious sponsorship (most of them Catholic or Jewish); moving westward (where one might have imagined the ethnic impact to be lower), Cincinnati in 1925 had nine general hospitals, of which four were sponsored by Protestant groups (chiefly Methodists), two by Catholics, and one by Jews. That year, 308 Catholic patients in Cincinnati had to enter a hospital, and 165 of them (54 percent) chose one of the three Catholic hospitals; so too, 54 of the 71 Jewish patients ( 76 percent) entered the Jewish hospital. (Among Protestants, the figures were lower, for those in the majority did not experience the same incentives.) To be sure, Catholic and Jewish hospitals served more than Catholic and Jewish patients-the CHA estimated that 49 percent of its patients were non-Catholic-and not every member of an ethic or religious group patronized the group's own hospitals. But a majority of Catholics did use the group's hospitals, and the figures may even have been slightly higher among Jews. $^{82}$

Early twentieth-century Catholic hospitals emphasized the human and spiritual, as well as medical, needs of their patients. "Nursing sisters" comforted patients and ensured that priests were available to give extreme unction to Catholic patients. ${ }^{84}$ The walls of Catholic hospitals frequently displayed crucifixes and paintings that displayed "the deepest Catholic piety." 85 And

80. ROSENBERG, supra note 78 , at 111 .

81. ROTHMAN, supra note 75 , at 123.

82. Id. at 123-24; see also STEVENS, supra note 77, at 23 (noting that more than eighty percent of the private and sectarian charitable hospitals existing in 1910 were established after 1880 , and that thirty-two percent were established in the decade beginning in 1900); id. at 29 (noting that "Illinois reported the largest cluster of Roman Catholic hospitals of any state in 1903 (43 out of a total of 118 hospitals).").

83. ROTHMAN, supra note 75, at 124; see also RoSENBERG, supra note 78, at 240 ("To be treated by a religious woman and to pay a modest sum for one's room and board transformed a hospital stay for Catholics into something less painful and humiliating than it would have in a large, nonsectarian-that is, Protestant-voluntary hospital.").

84. ROTHMAN, supra note 75 , at 124.

85. Id. at 124. 
Catholic physicians believed that prescribing medications for patients but ignoring the human and spiritual aspect of patient care was not an effective method of treatment. ${ }^{86}$ Jewish hospitals demonstrated a similar religious orientation. One of the stated reasons for the 1900 founding of Beth Israel Hospital on New York's lower East Side was to "have a hospital that should be conducted on strictly orthodox principles in its kitchen as well as in other respects." 87 Jewish patients who received treatments at Jewish hospitals also could be assured of receiving kosher foods and access to Yiddish-speaking physicians. $^{88}$

After the 1950s, however, sectarian hospitals discontinued their exclusive reliance on religion or ethnicity as a reason for selecting resident and attending physicians and began to place greater weight on the area of specialization or expertise as well as the merit of the physician:" "It became increasingly difficult to define what was Presbyterian about Presbyterian Hospital or Jewish about Mt. Sinai Hospital, and the answer could not be found in the characteristics of either the patients or the attending physicians." 90 Although Catholic hospitals are somewhat excepted from this trend, social and medical historians argue that Catholic hospitals of the second-half of the twentieth century "barely resembled" their predecessor hospitals of the early twentieth century. ${ }^{91}$ Similarly, the trustees of Montefiore Hospital in New York amended their charter in 1985 to eliminate the requirement that a majority of the board of trustees had to be Jewish. ${ }^{92}$

Very broadly, one might conclude that in the Western Christian tradition, medicine and religion: (1) enjoyed a close relationship in ancient and medieval times through healing rites, exorcisms, pilgrimages, and health care cults; (2) began to separate during (and did separate following) the Protestant Reformation and the turn of the seventeenth century with the rise of modern science and scientific medicine; and (3) grew closer together again with the development of dynamic psychiatry and the religion and health movement in the early

86. Id. at $124-25$.

87. Id. at 125 .

88. Id. at 125; see also ROSENBERG, supra note 78, at 178 ("German-speaking physicians whether Jewish or Christian might find attending positions in German and Jewish hospitals."); STARR, supra note 34, at 173 ("Discrimination was a principal reason for the formation of separate religious and ethnic hospitals. . . Catholics were afraid they might not be given last rites, and Jews feared they would have to eat nonkosher food and face ridicule for their appearance and rituals.").

89. ROTHMAN, supra note 75 , at 129-30.

90. Id. at 130.

91. Id. at 130; see also STEVENS, supra note 77, at 26 ("hence the survival of names such as Presbyterian, Methodist, Baptist, or Mount Sinai for hospitals which today are indistinguishable from nonsectarian institutions.").

92. ROTHMAN, supra note 75, at 130 ; see also STEVENS, supra note 77 , at 100 ("World War I confirmed that the United States was now one nation. . . . Local elites on boards of trustees continued to represent business and religious interests, but the old ethnic, religious, and national identifies of hospitals had blurred."). 
twentieth century. In the United States, medicine and religion shared a constantly evolving and interwoven relationship seemingly characterized by action and reaction, participation and withdrawal, competition and cooperation. Depending on when asked, one might describe American medicine and religion as incompatible, complimentary, ${ }^{93}$ or even augmentative, ${ }^{94}$ or as enemies or allies. ${ }^{95}$

\section{B. The History of Clinical Pastoral Education and American Hospital Chaplaincy}

When a hospital or other health care facility employs, contracts with, sponsors, or otherwise affiliates with a minister, priest, pastor, rabbi, or other similar person to provide pastoral care ${ }^{96}$ or religious or spiritual services in its facility, the provision of such care or services by that person generally is known as "health-care chaplaincy." "97 To simplify matters, this Article will refer to, and use as an example, chaplains who provide pastoral care in hospitals (hereinafter, "hospital chaplains"). Please note, however, that the legal principles discussed in this Article would apply equally to persons who provide pastoral care or religious or spiritual services in or through other types of health care organizations that constitute covered entities under the Privacy Rule, including nursing facilities, hospices, and home health agencies. ${ }^{98}$

93. See, e.g., Numbers \& Sawyer, supra note 35 , at 140 (noting that the roles of physician and priest throughout the Middle Ages were "complimentary").

94. See, e.g., Vanderpool, supra note 55, at 1254 (stating that medicine and therapy in seventeenth and eighteenth century America were viewed as "compatible with and at points augmentative").

95. See, e.g., Numbers \& Sawyer, supra note 35, at 134 (asking whether church and medicine are "enemies or allies").

96. From a Christian perspective, the phrase pastoral care means "the attempt to help others, through words, acts, and relationships, to experience as fully as possible the reality of God's presence and love in their lives." HOSPITAL MINISTRY: THE ROLE OF THE CHAPLAIN TODAY 46 (Lawrence E. Holst ed., 1985). Today, the phrase generally refers to the services provided by ordained ministers, priests, and other persons with designated religious roles, including deacons and members of Roman Catholic religious orders, to persons in need. Although the phrase primarily has Christian roots, other faith traditions, including Judaism, sometimes used the phrase analogously. Hunter, supra note 33, at 1975.

97. Hunter, supra note 33, at 1975.

98. See 45 C.F.R. $\$ 160.103$ (2005) (defining a health care provider to include "a provider of services (as defined in section 1861(u) of the [Social Security] Act, 42 U.S.C. 1395x(u))"); 42 U.S.C. $\$ 1395 x(u)(2005)$ (defining a provider of services to include a skilled nursing facility, home health agency, or hospice program, among other types of health care providers). Professional chaplains provide pastoral care and religious and spiritual services in a variety of healthcare settings including, but not limited to, facilities providing acute care, long-term care, assisted living, rehabilitation, mental health services, outpatient services, addiction treatment, care and services for mental retardation and developmental disability, and hospice and palliative care. See Professional ChAPLAINCY, supra note 1, at 5 (describing the healthcare settings for spiritual care). 
Late nineteenth and early twentieth century hospital chaplain services frequently were provided by retired, community clergypersons who had no special training beyond the experience gained from their local parishes. ${ }^{99}$ However, in the early part of the twentieth century, the "religion and health movement" began to explore the positive relationship between religion and modern medicine and proposed the placement of theological students in clinical settings. ${ }^{100}$

In 1923, Dr. William S. Keller placed theological students in a general hospital in Cincinnati and, in 1925, Congregational minister Anton T. Boisen developed a program at Worcester State Hospital in Massachusetts that studied the relationship between religion and mental disorders. ${ }^{101}$ Boisen's program, which later became known as "clinical pastoral education,"102 grew out of his dissatisfaction with traditional theological education of the day, "which was considered by many to be too abstract, too removed from life, too divorced from the practical tasks of ministry." $" 103$ Boisen believed that intensive clinical experience, not books, was the key to developing a theological understanding of human nature and effective pastoral care. ${ }^{104}$ The clinical pastoral education movement peaked in the 1930 s with the development of clinical pastoral training centers, the certification of chaplain supervisors, and the creation of staff chaplaincy positions in both mental and general hospitals, many of which still exist today. ${ }^{105}$

\section{Education and Certification of Hospital Chaplains}

Most of today's hospital chaplains hold college and seminary degrees or have other appropriate theological education, usually with an emphasis in biblical theology, dogmatics, church history, philosophy, or the arts and humanities. ${ }^{106}$ Most hospital chaplains also have been ordained, commissioned, or otherwise endorsed by their religious denominations. ${ }^{107}$ State law typically does not license hospital chaplains, although some hospital chaplains

99. Hunter, supra note 33, at 1977.

100. Id. (citing E. BRoOKS Holifield, A History of PASTORAL CARE IN AMERICA: From SALVATION TO SELF-REALIZATION (1985)).

101. Id. (citing EDWARD E. THORNTON, Professional EdUCATION FOR Ministry: A History OF CliniCAL PASTORAL EDUCATION (1970)); see also Lawrence E. Holst, Hospital Chaplain Between Worlds, in HEALTH/MEDICINE AND THE FAITH TRADITIONS: AN INQUIRY INTO RELIGION AND MEDICINE 293, 297 (Marin E. Marty \& Kenneth L. Vaux, eds., 1982) (explaining that clinical pastoral education began in 1925 in a state mental hospital in Worcester, Massachusetts).

102. Hunter, supra note 33, at 1977.

103. Holst, supra note 101, at 297.

104. Hunter, supra note 33, at 1977 (citing ANTON T. BOISEN, THE EXPLORATION OF THE INNER WORLD (1971)).

105. Id.

106. Holst, supra note 101, at 297.

107. Hunter, supra note 33, at 1977. 
who also practice specialized pastoral counseling are licensed under state law as pastoral counselors, psychologists, or marriage and family therapists. ${ }^{108}$

In addition to formal theological education, nearly all full-time professional hospital chaplains have trained for their ministries through participation in some level of clinical pastoral education ("CPE"). In the United States, the Association for Clinical Pastoral Education ("ACPE"), the National Association of Catholic Chaplains, and the National Association of Jewish Chaplains establish high standards for the professional practice of hospital chaplaincy and enforce such standards through rigorous certification and review procedures. ${ }^{109}$

The ACPE generally accredits three different levels of CPE for: (1) interns and beginning residents; (2) residents preparing for chaplaincy certification and residents seeking specialization in a particular clinical area; and (3) individuals training and preparing to be certified as CPE supervisors. ${ }^{110}$ Interns generally are defined as those individuals who participate in one or two units of CPE. ${ }^{111}$ Each unit of CPE includes approximately 400 hours of supervised education in a health care or institutional setting. ${ }^{112}$ Residents generally are defined as those individuals who participate in one or two years of a fulltime CPE program. ${ }^{113}$ Each year includes approximately 1,600 hours of supervised education in a health care or institutional setting. ${ }^{114}$ The ACPE requires individuals to complete 1,600 hours of CPE to become a board-certified chaplain. ${ }^{115}$ Individuals who want to obtain a specialization in hospice, pediatrics, cardiology, rehabilitation, or neurology chaplaincy can do so by completing additional $\mathrm{CPE}$ in the relevant setting. ${ }^{116}$

To be eligible to enter training to become a CPE supervisor, an individual must have completed at least four units, or 1,600 hours, of CPE. Upon completion of supervisory training, the individual is eligible to be certified by the ACPE as a CPE supervisor. CPE supervisors are permitted to develop and conduct $\mathrm{CPE}$ training for all ACPE-accredited programs.

108. Id.

109. Id.

110. Certification Commission, Ass'N for Clinical Pastoral Educ., ACPE Certification MANUAL 5 (2005), available at http://www.acpe.edu/acroread/ 2005_certification_manual.pdf.

111. Medicare Program; Changes to the Hospital Inpatient Prospective Payment Systems and Fiscal Year 2004 Rates, 68 Fed. Reg. 45,346, 45,425 (Aug. 1, 2003). Individuals also may undertake one or more units of CPE to be ordained into professional ministry or to obtain a doctoral degree with a specialty in pastoral counseling or related fields. Id.

112. Id.

113. Medicare Program; Changes to the Hospital Inpatient Prospective Payment Systems and Fiscal Year 2004 Rates, 68 Fed. Reg. at 45,425.

114. $I d$.

115. Id.

116. $I d$. 


\section{The Functions and Job Duties of Today's Hospital Chaplain}

As part of their job duties, hospital chaplains interact with patients and families, medical and nursing staff members, ethics committee and institutional review board members, hospital administrators, volunteers, and community members. Hospital chaplains perform many functions and services that are partly or mostly religious or spiritual in nature as well as several other functions and services that cannot be characterized solely by their religious or spiritual characteristics. ${ }^{117}$

The functions and services of today's hospital chaplain that are partly or mostly religious or spiritual in nature include, but certainly are not limited to: providing spiritual care, including grief and loss care; performing spiritual assessments of patients; performing patient risk screenings, which includes identifying those patients whose religious or spiritual conflicts may compromise recovery or satisfactory adjustment; charting spiritual care interventions in medical records; protecting patients from unwelcome forms of spiritual intrusion; reminding hospital workforce members and patients of the healing power of religious faith; facilitating spiritual issues relating to organ and tissue donation; designing and leading religious ceremonies of worship and ritual including prayer, meditation, reading of holy texts, worship and observance of holy days, blessings and sacraments, memorial services and funerals, rituals at the time of birth or other significant times of life-cycle transition, and holiday observances; making presentations concerning spirituality and health issues; training and supervising volunteers from religious communities who can provide spiritual care to the sick; conducting professional clinical education programs for seminarians, clergypersons, and religious leaders; developing congregational health ministries; educating students in the health care professions regarding the interface of religion and spirituality with medical care; offering patients, family members, and staff an emotionally and spiritually "safe" professional from whom they can seek counsel or guidance; engaging in research activities relating to the development of spiritual assessment and spiritual risk screening tools; and promoting research relating to spiritual care at national conventions. ${ }^{118}$

Hospital chaplains also perform and provide a number of other functions and services that cannot be solely characterized by their religious or spiritual nature, including: communicating with caregivers; facilitating staff communications; resolving conflicts among staff members, patients, and family members; referring patients to internal and external resources including other health care providers, patient advocates, and community and social resources; providing "decedent care"; ${ }^{119}$ providing institutional support during organizational

117. Professional ChaPLAINCY, supra note 1 , at 8-10.

118. $I d$.

119. See, e.g., Texas Health Resources, Harris Methodist Southwest Hospital: Spiritual Care, at http://www.texashealth.org/hospitals/default.asp?level=2\&id=AB1CD4945F6643DA 8A99EE4C39970443\&enorgid=F9DC671D200E43C194F983A4E510B2EB (last visited Apr. 
change or crisis; participating in medical rounds and patient care conferences; participating in interdisciplinary education; assisting patients and families in executing or completing advance directives; participating in ethics committees and institutional review boards; clarifying the application of institutional policies and behaviors to patients, community clergy, and religious organizations; conducting in-service education; interpreting and analyzing cultural traditions that may impact clinical services; representing community issues and concerns to the organization; and acting as "cultural brokers" between institutions, patients, family members, and staffs. ${ }^{120}$ In summary, hospital chaplains do not limit their services to individuals with needs that are explicitly defined in religious or spiritual terms. ${ }^{121}$

\section{E. The Role of Today's Hospital Chaplain}

\section{Hospital Chaplains as Members of the Health Care Team}

Because hospital chaplains provide a range of therapeutic, supportive, and administrative services, "their work often closely resembles, in certain respects, that of psychiatrists, psychologists, psychiatric nurses, social workers, and patient representatives."122 Although they do not practice medicine (and are prohibited by state law from doing so without obtaining the appropriate education and licensure), ${ }^{123}$ hospital chaplains believe that religion and spirituality support the fundamental aims of health care and view their ministries as involved in the healing process. "Consequently, they view themselves as significant members of the healthcare team, and increasingly are being viewed in that way by the medical professions." 124 Rodney Hunter, Professor of Pastoral Theology at Emory University, similarly believes that the identity of hospital chaplains is based not only on religion, but also health and healing generally. ${ }^{125}$

Additional literature supports the inclusion of the hospital chaplain in the health care team. Harold Koenig, Director of the Center for the Study of Religion/Spirituality and Health at Duke University, recommends that chaplains: (1) be fully integrated into the multidisciplinary care team; (2) participate in morning and afternoon rounds with physicians and nurses; (3) partici-

24, 2005) (on file with the Indiana Health Law Review) (listing services offered by the hospital's pastoral care department).

120. Hunter, supra note 33, at 1976.

121. Id. at 1976.

122. Id.

123. See, e.g., TEX. OCC. CODE ANN. $\S 155.001$ (Vernon 2004) ("A person may not practice medicine in this state [of Texas] unless the person holds a license issued under the [Texas Medical Practice Act]").

124. Hunter, supra note 33 , at 1976-77.

125. Id. (citing CHAPLAINCY SERVICES IN CONTEMPORARY HEALTHCARE 2 (Laurel Arthur Burton ed., 1992)). 
pate in discharge planning. ${ }^{126}$ In situations involving conflicts about treatment decisions due to a patient's or a family's religious beliefs, Robert Orr, Director of Clinical Ethics at The Center for Bioethics and Human Dignity, also recommends that chaplains serve as consultants to the health care team. ${ }^{127} \mathrm{Orr}$ emphasizes the ability of chaplains to articulate questioned beliefs in a way that makes both parties to the conflict clearly understand the issues involved. ${ }^{128}$

A review of current hospital policies and procedures indicates that many hospitals specifically identify their chaplains as members of the health care team. The Pastoral Care Department of Parkland Health and Hospital System in Dallas, Texas, explains that, "The chaplain is a part of the healthcare team. Patient care situations that involve the spiritual, religious and ethical issues inherent in medicine and healing should involve the chaplain."129 The Johns Hopkins Hospital treats chaplains as members of the multi-disciplinary health care team that reviews cases involving the withdrawal of life support. ${ }^{130}$ The University of Virginia Health System ("UVA") explains that, "hospital chaplain-counselors, as members of the health care team, endeavor to provide pastoral care and counseling." 131 The duties of UVA's hospital chaplains include "participat[ing] in staff meetings, family conferences, and discharge planning." "132

As members of the health care team, many hospital chaplains "chart," meaning that they document the religious or spiritual care or services provided to patients in their medical records just like physicians, nurses, and other health care professionals document the medical care they provide to patients. A 1996 article reports that the chaplains of Hennepin County Medical Center, a 400-bed general teaching hospital and Level One trauma center located in downtown Minneapolis, Minnesota (hereinafter, "Hennepin"), chart the pastoral care provided to patients by entering a handwritten note in each patient's medical records identifying the chaplain's involvement in the

126. KOENIG ET AL., supra note 2, at 451.

127. Robert D. Orr \& Leigh B. Genesen, Requests for 'Inappropriate' Treatment Based on Religious Beliefs, 23 J. MED. ETHICs 142, 146 (1997).

128. Id.

129. Parkland Health \& Hospital System, Patients and Visitors: Pastoral Care, at http://www.parklandhospital.com/patients_visitors/pastCare.html (last visited Apr. 21, 2005) (on file with the Indiana Health Law Review).

130. Procedure for Withdrawal of Life Support in the MICU/MCP $§ 2.1 .1 .1$, in THE JOHNS Hopkins Hospital Medical Nursing Service Standards of Care Manual (2001) (explaining that before withdrawing life support, there shall be a "Family conference with family members, nursing, physicians, and other multi-disciplinary team members as needed, (i.e., chaplain, social work, respiratory therapy).").

131. University of Virginia Health System, Housestaff Policy Manual: Chaplains, at http://www.healthsystem.virginia.edu/internet /housestaff/policy-manual/chaplains.cfm (last modified Oct. 17, 2002) (on file with the Indiana Health Law Review).

132. Id. 
patient's care. ${ }^{133}$ Although the Hennepin chaplains reportedly chart almost every patient interaction, many other hospital chaplains chart on a more limited basis. For example, a hospital chaplain may chart patient encounters that result from a specific physician order or nurse referral for spiritual care in order to let the physician or nurse know that the hospital chaplain followed or responded to the physician's order or nurse's referral. However, the same hospital chaplain may not chart other encounters that were not preceded by a physician order or nurse referral. When hospital chaplains chart patient encounters, they will have access to other PHI contained in the chart. In fact, it would be almost impossible for a hospital chaplain to write a note in a patient's chart while not seeing the other contents of the chart.

\section{Hospital Chaplains: In-Between the Worlds of Religion and Medicine}

Because the identity of many chaplains is based both on health and healing generally, as well as religion, the literature sometimes refers to the hospital chaplain not as a member of the health care team but, instead, as "walk[ing] between the worlds of religion and medicine."134 Reverend Lawrence Holst, former Chair of the Department of Pastoral Care at Illinois' Lutheran General Hospital, explains that the hospital chaplain:

[I]s both pastor and clinician, theologically educated and clinically trained, endorsed by both church and hospital. A hospital chaplain is of the church but not in the parish. He is nobody's pastor but everybody's pastor. His salary is from the hospital, his mandate from the church. By history and tradition he is closer to his colleagues in the parish ministry, but his daily interactions are with physicians and nurses. In many hospitals the chaplain's garb is a white or blue clinical coat inscribed with a cross - symbols of medicine and religion. Often these two worlds are complementary, but sometimes they are contradictory. ${ }^{135}$

Holst further explains that the hospital chaplain:

[W]alks between (1) a faith assumption that the gospel he proclaims has validity and reality despite how, or even whether, it is internally appropriate by the patient and (2) a

133. Rob A. Ruff, "Leaving Footprints": The Practice and Benefits of Hospital Chaplains Documenting Pastoral Care Activity in Patients' Medical Records, 50 J. PAST. CARE 383, 38391 (1996).

134. Holst, supra note 101, at 293.

135. Id. 
clinical assumption that his faith will have dynamic, functional value for that patient .... ${ }^{136}$

The characterization of the hospital chaplain not as a member of the health care team but, instead, as "in-between" the worlds of medicine and religion may provide one explanation for HHS' statement that, "clergy or other religious practitioners that provide solely religious healing services are not health care providers" under the Privacy Rule. ${ }^{137}$

\section{Applying The Privacy Rule To Hospital Chaplains}

\section{A. The Privacy Rule's Use and Disclosure Requirements}

The Privacy Rule generally establishes three tiers of patient permission, one of which must be satisfied before a covered entity or one of its workforce members ${ }^{138}$ can use or disclose PHI. First, the Privacy Rule requires no form of prior patient permission whatsoever before a covered entity, or employee or workforce member thereof, may use or disclose PHI to carry out the covered entity's treatment, ${ }^{139}$ payment, ${ }^{140}$ or health care operations activities, ${ }^{141}$

136. Id. at 303 (emphasis in original).

137. Id.

138. The Privacy Rule defines workforce to mean "employees, volunteers, trainees, and other persons whose conduct, in the performance of work for a covered entity, is under the direct control of such entity, whether or not they are paid by the covered entity." 45 C.F.R. $\S$ 160.103 (2005). Hospital-employed chaplains, chaplains that the hospital contracts with on an independent contractor basis, or otherwise affiliate with, as well as theology students and CPE residents satisfying their clinical pastoral education requirements in the hospital, likely would constitute hospital workforce members.

139. See text accompanying note 149 , infra, for the definition of treatment.

140. The Privacy Rule defines payment to include:

(1) The activities undertaken by: ... (ii) A [covered] health care provider or health plan to obtain or provide reimbursement for the provision of health care; and (2) The activities in paragraph (1) of this definition relate to the individual to whom health care is provided and include, but are not limited to: (i) Determinations of eligibility or coverage (including coordination of benefits or the determination of cost sharing amounts), and adjudication or subrogation of health benefit claims; (ii) Risk adjusting amounts due based on enrollee health status and demographic characteristics; (iii) Billing, claims management, collection activities, obtaining payment under a contract for reinsurance (including stoploss insurance and excess of loss insurance), and related health care data processing; (iv) Review of health care services with respect to medical necessity, coverage under a health plan, appropriateness of care, or justification of charges; (v) Utilization review activities, including precertification and preauthorization of services, concurrent and retrospective review of services; and (vi) Disclosure to consumer reporting agencies of any of the following protected health information relating to collection of premiums or reimbursement ....

45 C.F.R. $\S 164.501$ (2005).

141. See 45 C.F.R. $\$ 164.506$ (c)(1) (2005) (permitting a covered entity to use and disclose PHI "for its own treatment, payment, or health care operations activities" without any form of 
or one of twelve public policies activities. ${ }^{142}$ Second, the Privacy Rule permits covered entities to use and disclose certain limited directory information, ${ }^{143}$ to disclose certain relevant information to persons involved in a patient's care including family members and friends, and to disclose certain relevant information for notification purposes, but only if the covered entity informs the patient in advance of the use or disclosure, the covered entity gives the patient the opportunity to agree to or prohibit or restrict the disclosure, and the patient actually agrees to the disclosure. ${ }^{144}$ The patient can provide his or her agree-

prior patient permission); see also 45 C.F.R. $§ 164.501$, which defines health care operations, in relevant part, to mean:

[A]ny of the following activities of the covered entity . . . : (1) Conducting quality assessment and improvement activities, including outcomes evaluation and development of clinical guidelines, provided that the obtaining of generalizable knowledge is not the primary purpose of any studies resulting from such activities; population-based activities relating to improving health or reducing health care costs, protocol development, case management and care coordination, contacting of health care providers and patients with information about treatment alternatives; and related functions that do not include treatment; (2) Reviewing the competence or qualifications of health care professionals, evaluating practitioner and provider performance, health plan performance, conducting training programs in which students, trainees, or practitioners in areas of health care learn under supervision to practice or improve their skills as health care providers, training of non-health care professionals, accreditation, certification, licensing, or credentialing activities; (3) Underwriting, premium rating, and other activities relating to the creation, renewal or replacement of a contract of health insurance or health benefits, and ceding, securing, or placing a contract for reinsurance of risk relating to claims for health care (including stop-loss insurance and excess of loss insurance), provided that the requirements of $\$ 164.514(\mathrm{~g})$ are met, if applicable; (4) Conducting or arranging for medical review, legal services, and auditing functions, including fraud and abuse detection and compliance programs; (5) Business planning and development, such as conducting costmanagement and planning-related analyses related to managing and operating the entity, including formulary development and administration, development or improvement of methods of payment or coverage policies; and (6) Business management and general administrative activities of the entity, including, but not limited to: (i) Management activities relating to implementation of and compliance with the requirements of this subchapter; (ii) Customer service, including the provision of data analyses for policy holders, plan sponsors, or other customers, provided that protected health information is not disclosed to such policy holder, plan sponsor, or customer. (iii) Resolution of internal grievances; (iv) ... due diligence ...; and (v) Consistent with the applicable requirements of $\S 164.514$, creating de-identified health information ... and fundraising for the benefit of the covered entity [for which an individual authorization is not required as described in $\S 164.514(\mathrm{e})(2)$.]

142. These twelve public policy activities are listed at 45 C.F.R. $\S 164.512$ (a) to (l) (2005).

143. 45 C.F.R. $\S 164.510$ (a)(i)(A)-(D) (2005) (defining directory information to include: “(A) The individual's name; (B) The individual's location in the covered health care provider's facility; (C) The individual's condition described in general terms that does not communicate specific medical information about the individual [i.e., "good," "fair," "poor," "stable"]; and (D) The individual's religious affiliation ....").

144. Id. 
ment orally. ${ }^{145}$ Third, the Privacy Rule requires the patient's prior written authorization before a covered entity or one of its workforce members may use or disclose PHI for any other activity that is not allowed under the first two tiers of patient permission. The authorization form signed by the patient must contain a number of specific elements and statements listed in the Privacy Rule. $^{146}$

Because most hospitals chaplains would prefer to use PHI without having to ensure that the hospital has already obtained a valid, written authorization from the patient, hospital chaplains usually attempt to fit their activities within the first tier of patient permission, which includes those treatment, payment, and health care operations activities that require no form of prior patient permission whatsoever. ${ }^{147}$ Based on the literature and current hospital practices discussed in Part II of this Article characterizing the hospital chaplain as a member of the health care team, one might argue that the hospital chaplain's activities constitute treatment activities. The Privacy Rule defines treatment as:

[T] he provision, coordination, or management of health care and related services by one or more health care providers, including the coordination or management of health care by a health care provider with a third party; consultation between health care providers relating to a patient; or the referral of a patient for health care from one health care provider to another. ${ }^{148}$

To constitute treatment, one or more health care providers, or a health care provider with a third party, must be providing, coordinating, or managing health care and related services. The Privacy Rule defines health care as:

[C]are, services, or supplies related to the health of an individual. Health care includes, but is not limited to, the following: (1) Preventive, diagnostic, therapeutic, rehabilitative, maintenance, or palliative care, and counseling, service, assessment, or procedure with respect to the physical or mental condition, or functional status, of an individual or that

145. Id. ("The covered entity may orally inform the individual of and obtain the individual's oral agreement or objection to a use or disclosure permitted by this section").

146. See 45 C.F.R. $\$ 164.508$ (c)(1),(2) (2005).

147. See, e.g., Lerrill White \& Rod Pierce, Creating HIPAA Compliant Policies and Procedures, APC NEWS, July/Aug. 2002 (arguing that hospital chaplains are health care professionals involved in treatment of patients), reprinted in Ass'n of Prof'1 Chaplains, Professional Resources, Reading Room: HIPAA and Pastoral Care, at http://www.professionalchaplains.org/professional-chaplain-services-resources-reading-roomhippa-3.htm (last visited Apr. 21, 2005) (on file with the Indiana Health Law Review).

148. 45 C.F.R. $\S 164.501$ (2005). 
affects the structure or function of the body; and (2) Sale or dispensing of a drug, device, equipment, or other item in accordance with a prescription. ${ }^{149}$

Based on these definitions, one could attempt to argue that hospital chaplains either are health care providers ${ }^{150}$ or third parties that work with health care providers to provide, coordinate, and manage health care, which is defined to include palliative care, counseling, and assessment servicesservices identified in Part II of this Article as the responsibility of hospital chaplains. Based on this argument, one could tentatively conclude that hospital chaplains engage in treatment activities. However, HHS explains in its preamble:

[T] he Department [HHS] clarifies that "health care" as defined under the rule does not include methods of healing that are solely spiritual. Therefore, clergy or other religious practitioners that provide solely religious healing services are not health care providers within the meaning of this rule . . . ${ }^{151}$

The import of these two sentences is not clear. For example, does HHS believe that the services that clergy and other religious practitioners provide always constitute "methods of healing that are solely spiritual" or "solely religious services"? Or, does HHS believe that clergy and other religious practitioners can provide a range of services, some of which are spiritual or religious in nature and others that constitute "health care"? If the latter is true, would HHS classify the clergy and other religious practitioners who provide a range of services, including counseling and assessment services that fall within the definition of health care, as "health care providers"?

149. 45 C.F.R. $\S 160.103$ (2005).

150. The Privacy Rule specifically defines a health care provider as one of three types of persons or organizations: "[1] a provider of services (as defined in ... 42 U.S.C. $\$ 1395 x(\mathrm{u})$ ) [; 2] a provider of medical or health services (as defined in ... 42 U.S.C. $\$ 1395 x(s)$ ) [; and 3] any other person or organization who furnishes, bills, or is paid for health care in the normal course of business." Id. Neither a hospital chaplain, clergyperson, nor any other type of religious practitioner is listed as a provider of services under 42 U.S.C. $\S 1395 \times(u)$ (which lists institutional or organizational health care facilities, including hospitals, nursing facilities, and home health agencies), or a provider of medical or health services under 42 U.S.C. $§ 1395 \times($ s) (which lists individual health care providers, including physicians, nurses, and social workers). However, one could still argue that a hospital chaplain constitutes a health care provider under the third prong of the definition, which applies to "any other person ... who furnishes ... health care in the normal course of business." 45 C.F.R. $\$ 160.103$ (emphasis added). However, to fall under the third prong, the person must be furnishing health care and, thus, the analysis would run back into HHS' preamble language which specifically states that health care does not include methods of healing that are solely spiritual or religious. See infra note 151 and accompanying text.

151. Standards for Privacy of Individually Identifiable Health Information, 65 Fed. Reg. 82,462, 82,568 (Dec. 28, 2000). 
As discussed in more detail in Part III.B, several arguments exist that support the conclusion that some services provided by hospital chaplains fall within the definition of "health care." If, however, one interprets the preamble to conclude that hospital chaplains only provide "methods of healing that are solely spiritual" or "solely religious services," the technical result is that the hospital must obtain the prior written authorization of the patient if the chaplain's activities are not otherwise permitted under the first or second tiers of patient permission. A hospital chaplain's activities generally would not fall within the definitions of payment ${ }^{152}$ or health care operations ${ }^{153}$ for purposes of the first tier of patient permission. With a few potential exceptions, a hospital chaplain's activities would not fall within one of the twelve public policy activities also permitted under the first tier of patient permission. ${ }^{154}$

152. See supra note 140.

153. See supra note 141. At first glance, the term health care operations might appear to include the case management and care coordination activities for which hospital chaplains are responsible as discussed in supra Part II of this Article. However, a closer examination of the definition of health care operations reveals that these activities must be population-based to qualify as health care operations. 45 C.F.R. $\S 164.501$ (2005) (defining health care operations to include "population-based activities relating to ... case management and care coordination"). However, most of the activities in which hospital chaplains engage are patient-specific, not population-based.

154. The twelve public policy exceptions relate to: (1) uses and disclosures required by law; (2) uses and disclosures for certain, specific public health activities; (3) disclosures about victims of abuse, neglect, or domestic violence; (4) uses and disclosures for certain health oversight activities; (5) disclosures for judicial and administrative proceedings; (6) disclosures for law enforcement purposes; (7) uses and disclosures about decedents; (8) disclosures to organ procurement organizations for cadaveric organ, eye, or tissue donation; (9) uses and disclosures for research activities; (10) uses and disclosures to avert a serious threat to health or safety; (11) uses and disclosures for specialized government functions; and (12) disclosures for workers' compensation purposes. 45 C.F.R. $\S 164.512$ (a) to (1) (2005). Under the first public policy exception, a covered entity may use or disclose PHI without any form of prior patient permission if a federal or state law requires the use or disclosure. Id. $\S 164.512$ (a). As discussed in more detail in Part III.B.3, below, the Joint Commission on Accreditation of Healthcare Organizations as well as the regulations implementing the Texas Hospital Licensing Law and, perhaps, other state hospital licensing laws, require hospitals to address the spiritual needs of their patients. To the extent that addressing the spiritual needs of patients requires hospital chaplains to access and use PHI, the public policy exception set forth at 45 C.F.R. $\S$ 164.512(a) potentially applies. The strength of this argument is addressed in infra Part III.B.3. Other public policy exceptions are potentially applicable in certain limited situations. For example, one of the public policy exceptions permits covered entities and their workforce members to disclose PHI relating to decedents to coroners, medical examiners, and funeral directors. Id. $\S 164.512(\mathrm{~g})$. As discussed in note 119 and the accompanying text in Part II.D, supra, some hospitals require their chaplains to engage in "decedent care." To the extent this care includes communications with funeral directors, coroners, or medical examiners, the public policy exception set forth at 45 C.F.R. $\S 164.512(\mathrm{~g})$ (addressing uses and disclosures of decedent information) may apply. Finally, to the extent a hospital chaplain wishes to use or disclose PHI to engage in research about the positive health outcomes associated with religious interventions, for example, the chaplain may attempt to satisfy all of the applicable elements of the research public policy exception set forth 45 C.F.R. § 164.512(i). 
Under the second tier of patient permission, a hospital chaplain could receive a patient's directory information, defined to include only the patient's name, location in the hospital, general condition described in one word, and religious affiliation (collectively, "directory information") if the patient has agreed to the disclosure of such information. ${ }^{155}$ Although hospital chaplains who have access only to directory information still could identify and locate patients within the hospital, ${ }^{156}$ many of their other roles and job duties, such as participating in ethics committees, hospital rounds, and patient care meetings, would be severely restricted or prohibited. If the hospital chaplain desires access to information beyond directory information, the third tier of patient permission would require the patient to authorize the hospital chaplain's access. The authorization form signed by the patient must contain a laundry list of required elements and statements, including a specific statement identifying the hospital chaplain by title or office as the recipient of the information as well as a statement identifying the specific purposes for which the chaplain would be using the patient's information. ${ }^{157}$ Again, this analysis applies only if one assumes that the services provided by hospital chaplains are limited to "methods of healing that are solely spiritual" or "solely religious services."

155. 45 C.F.R. $\S 164.510$ (a)(ii) (permitting disclosures of directory information to members of the clergy). Under this regulation, a hospital may disclose to a local Catholic Priest, for example, the names, locations, and general conditions of those Catholic patients who have orally agreed to have their information included in the facility directory. Although the Office for Civil Rights has confirmed in an electronically published "frequently-asked question" that hospitals may disclose faith-related directory information to community clergypersons, see U.S. Dep't Health \& Human Services, Questions and Answers: Privacy of Health Information/HIPAA, Answer ID 357, at http://answers.hhs.gov/cgibin/hhs.cfg/php/enduser/std_adp.php?p_sid $=$ xwnBYsBh\&p_lva $=483 \&$ p_faqid $=357 \& p$ _crea ted $=1040407954 \& p \_s p=c F 9 z \mathrm{zmNoPTEmcF} 9 \mathrm{ncmlkc} 29 \mathrm{ydD} 0 \mathrm{mcF} 9 \mathrm{yb} 3 \mathrm{df} Y 250 \mathrm{PTImcF} 9 \mathrm{zZW}$ FyY2hfdGV4dD1jbGVyZ3kmcF9jYXRfbHZsMT03JnBfY2F0X2×2bDI9fmFueX4mcF9wY WdIPTE*\&p_li= (last updated Mar 3, 2003) (on file with the Indiana Health Law Review), many individuals reportedly believe that the Privacy Rule interferes with such disclosures. See, e.g., Ann Rodgers-Melnick, Privacy Rules MayLimit Clergy Hospital Visits, PITTSBURGH PosTGAZETTE, Feb. 28, 2003, at E7.

156. The Privacy Rule only regulates covered entities' uses and disclosures of PHI. 45 C.F.R. $\S \S 164.500,164.502$ (2005). The Privacy Rule does not prohibit, limit, or otherwise regulate a patient's decision to share, use, or disclose his or her own PHI. A hospital chaplain who only has access to directory information could continue to identify and locate patients within the hospital but would have to work harder to obtain (i.e., by asking the patient about) other relevant PHI that may assist the chaplain in his or her spiritual assessment and provision of spiritual services to the patient.

157. See 45 C.F.R. $\S 164.508(c)(1)$-(2) (2005) (requiring authorization forms to include statements identifying the specific purpose for which the information will be used and the persons, or classes of persons, who will be using the patient's information). 


\section{B. Arguments Supporting Hospital Chaplains' Access to PHI beyond Directory Information}

However, several arguments support hospital chaplains' access to PHI beyond directory information without the prior written authorization of the patient who is the subject of the PHI. These arguments are based on: (1) hospital chaplains' job duties, which typically extend beyond the provision of "solely religious" and "solely spiritual services"; (2) HHS' failure to distinguish hospital-employed, contracted, or affiliated chaplains from community clergypersons; (3) state laws and Joint Commission on Accreditation of Healthcare Organizations standards requiring hospitals to address patients' spiritual needs; (4) numerous studies that characterize religion as an epidemiologically protective factor; (5) statements by the Medicare Program acknowledging that pastoral care has a beneficial and therapeutic effect on patients' medical conditions; and (6) the lack of any reported cases involving hospital chaplains' inappropriate use or disclosure of PHI. Each of these arguments is discussed in more detail below.

\section{Hospital Chaplains Provide Services Other than "Solely Religious" or "Solely Spiritual" Services}

The preamble states that health care does not include methods of healing that are "solely spiritual," and that clergy or other religious practitioners that provide "solely religious" healing services are not health care providers. ${ }^{158}$ However, all of the services provided by hospital chaplains cannot be characterized as solely spiritual or religious. As discussed in more detail in Part II.D, hospital chaplains provide many non-religious services including, but certainly not limited to, coordinating referrals to other support services including patient advocates, financial services, social workers, and psychologists; communication with caregivers; facilitation of hospital staff communication; conflict resolution among staff members, patients, and family members; paperwork relating to death and coordination of transfers of decedents to the morgue; and participation in institutional ethics committees and institutional review boards. Because hospital chaplains provide palliative, counseling, and other services that are not solely religious or spiritual in nature and that could constitute the coordination or management of health care, an argument exists that hospital chaplains are health care providers under the Privacy Rule. ${ }^{159}$

158. Standards for Privacy of Individually Identifiable Health Information, 65 Fed. Reg. $82,462,82,568$ (Dec. 28, 2000).

159. See supra note 150 (defining health care provider); see also Joseph J. Driscoll, HIPAA Calling the Question: Is the Chaplain a Health Care Professional? VISION, May 2003, at 4, available at http://www.nacc.org/docs/resources/HIPAA_Calling_the_Question.pdf (arguing that the hospital chaplain is a health care professional); $i \bar{d}$. at 5 (arguing that "In principle, the chaplain as a health care professional has full access just as any other member of the team"); 


\section{HHS Fails to Distinguish between Hospital Chaplains and Community Clergypersons}

Neither the Privacy Rule nor its voluminous preamble recognizes the hospital chaplain as distinct from the community clergyperson. The only specific religious practitioners HHS identifies or discusses are "members of the clergy," 160 and such discussion usually occurs in the context of allowing clergy access to directory information. Accordingly, one may argue that HHS does not understand the distinction between community clergy and hospital chaplains $^{161}$ and that HHS should: (1) distinguish between clergy and chaplains; and (2) clarify that clergy only have access to directory information and that chaplains have access to the PHI necessary to address the spiritual needs of their patients.

The term clergy generally refers to the duly authorized community representatives of the various faith groups. For example, the Texas Rules of Evidence, which establishes a confidential privilege relating to communications to members of the clergy, defines the term clergy to mean "a minister, priest, rabbi, accredited Christian Science Practitioner, or other similar functionary of a religious organization or an individual reasonably believed so to be by the person consulting with such individual."162 On the other hand, the

Michele LeDoux Sakurai, HIPAA \& Privacy: Regulations Impacting Spiritual Care in Health Care, Vision, Oct. 2001, at 4 ("Chaplains may find themselves advocating for their position as members of the interdisciplinary team . . ."), available at http://www.nacc.org/vision/ highlights/2001/oct2001-hipaa.htm; Lerrill White, Pastoral Care Providers are Members of the Healthcare Team in Accordance with the Regulations of the Department of Health \& Human Services, APC NEWS, Jan./Feb.2003, (revised Jan. 2005) (arguing that pastoral care providers are health care providers for purposes of the Privacy Rule), reprinted in Ass'n of Prof'1 Chaplains, Professional Resources, Reading Room: HIPAA and Pastoral Care, at $\mathrm{http}: / / \mathrm{www}$.professionalchaplains.org/professional-chaplain-services-resources-reading-roomhippa-5.htm (last visited Apr. 21, 2005) (on file with the Indiana Health Law Review).

160. See, e.g., 45 C.F.R. 164.510(a)(ii)(A) (2005) (explaining that covered health care providers may disclose to members of the clergy: (A) The individual's name; (B) The individual's location in the covered health care provider's facility; (C) The individual's condition described in general terms that does not communicate specific medical information about the individual; and (D) The individual's religious affiliation . . . " (emphasis mine); see also Standards for Privacy of Individually Identifiable Health Information, 65 Fed. Reg. at 82,568 (stating that, "'Health care' ... does not include methods of healing that are solely spiritual. Therefore, clergy or other religious practitioners that provide solely religious healing services are not health care providers within the meaning of this rule ....") (emphasis added).

161. See, e.g., Lerrill White \& Rod Pierce, HIPAA Regulations' Impact on Visitation by Clergy, Lay Ministers and Faith Group Representatives, APC NEWs, May/June 2002 (distinguishing hospital chaplains from community clergy and faith group representatives) reprinted in Ass'n of Prof'l Chaplains, Professional Resources, Reading Room: HIPAA and Pastoral Care, $a t \mathrm{http}: / / \mathrm{www}$.professionalchaplains.org/professional-chaplain-services-resources-readingroom-hippa-2.htm (last visited Apr. 21, 2005) (on file with the Indiana Health Law Review); Letter from The National Associations of Catholic Chaplains, to Colleagues (Mar. 3, 2003) (on file with author) ("The wording of the Rule does not offer a clear distinction between "Area Clergy" and "Professional Chaplain").

162. TEX. R. EVID. 505(a)(1). 
term chaplain specifically refers to those individuals who are associated with a particular organization and who are charged with providing emotional, pastoral, or spiritual care to members of the organization. For example, the American Heritage Dictionary defines a chaplain as, "[a] member of the clergy who conducts religious services for an institution, such as a prison or hospital." "63 These definitions recognize an important distinction between clergy and chaplains: clergy are individuals authorized to represent their particular faith groups in the community, while chaplains are individuals employed by, or otherwise associated with, institutions and whose roles include providing spiritual and other services to members of the institution. It follows that the phrase hospital chaplain would refer to an individual employed by a hospital who is specially trained to provide pastoral care and other services to patients, family members, and other individuals associated with the hospital. Thus, one could argue that HHS' use of the term clergy in connection with accessing directory information, ${ }^{164}$ and its failure to distinguish community clergy from hospital chaplains is evidence that HHS is unaware of the unique role of the hospital chaplain. ${ }^{165}$

Although the deadline for submitting comments relating to the Privacy Rule has long since passed, ${ }^{166}$ one suggestion is for the ACPE and other professional chaplain associations to continue submitting questions to the Office for Civil Rights ("OCR"), the office within HHS responsible for enforcing the Privacy Rule. ${ }^{167}$ Although the OCR will not provide individual responses, the OCR may, after receiving a sufficient number of questions relating to the same issue, respond by publishing a new "frequently-asked question" or guidance document distinguishing between clergy and chaplains and addressing whether hospital chaplains may access PHI beyond directory information. ${ }^{168}$

163. THE AMERICAN HERITAGE DiCTIONARY OF THE ENGLiSh LANGUAGE (4th ed. 2000).

164. See, e.g., 45 C.F.R. $\$ 164.510$ (a)(ii)(A)(explaining that covered health care providers may disclose directory information to "members of the clergy") (emphasis added).

165. See, e.g., Harold Y. Vanderpool, Is Religion Therapeutically Significant?, $16 \mathrm{~J}$. RELIGIOUS HEALTH 255 (1977) ("Our most common visual image of this relationship is probably that of a chaplain visiting a large hospital.").

166. HHS issued its last set of proposed modifications relating to the Privacy Rule on March 27, 2002. See Standards for Privacy of Individually Identifiable Health Information, 67 Fed. Reg. 14,776 (proposed Mar. 27, 2002). The time period for submitting comments relating to this proposed rule ended on April 26, 2002. See id.

167. OCR accepts comments relating to the Privacy Rule by electronic mail at OCRPrivacy@hhs.gov. See U.S. Dep't of Health \& Human Servs., Office of Civil Rights HIPPA: How to Contact the Office for Civil Rights (OCR), at http://www.hhs.gov/ocr/ contact.html (last revised July 14, 2003) (on file with the Indiana Health Law Review) (explaining that the OCR will not provide individual responses to electronic mail but will respond to concerns of general interest through development of new "frequently-asked questions" and published guidance documents).

168. Id. Although several health care attorneys, including myself, have submitted comments to the OCR relating to the use of PHI by hospital chaplains, the OCR has not yet issued a "frequently-asked question" or guidance document addressing whether hospital chaplains may access the PHI of inpatients. However, the OCR has confirmed that community clergypersons can access directory information relating to patients of their own faith tradition. 


\section{JCAHO Standards and State Laws Require Hospitals to Address Patients' Spiritual Needs}

The Joint Commission on Accreditation of Healthcare Organizations ("JCAHO") is an independent, not-for-profit organization that evaluates and accredits more than 16,000 health care organizations and programs in the United States, including hospitals. Hospitals and other health care organizations that are eligible for certification as a provider under the federal Medicare Program can choose to be surveyed by JCAHO. If, following the survey, JCAHO determines that the hospital is in substantial compliance with the relevant JCAHO standards, ${ }^{169}$ the hospital will earn JCAHO accreditation and also will be "deemed" to comply with the federal Centers for Medicare and Medicaid Services' ("CMS"') requirements for hospitals, known as the "Conditions of Participation for Hospitals." 170

One of JCAHO's hospital accreditation standards explains that, "[e]ach patient has a right to have his or her cultural, psychosocial, spiritual, and personal values, beliefs, and preferences respected."171 The same standard also explains that, "[t]he hospital [must] accommodate[] the right to pastoral and other spiritual services for patients." 172 With respect to end-of-life care, JCAHO's standards further explain that, "[t]he hospital [must] provide[] care that ... addresses the patient's and his or her family's psychosocial and spiritual needs." 173

U.S. Dep't of Health \& Human Servs., Questions and Answers: Privacy of Health Information/ HIPAA, Answer ID 483, at http://answers.hhs.gov/cgi-bin/hhs.cfg/php/enduser/std_adp.php?p_ sid $=V N m 3 x u D h \& p \_l v a=\& p \_$faqid $=483 \&$ p_created $=1067889406 \& p \_s p=c F 9 z \mathrm{zmNoPTEmc}$ F9ncmlkc29ydD0mcF9yb3dfY250PTImcF9zZWFyY2hfdGV4dD1jbGVyZ3kmcF9jYXRfb HZsMT03JnBfY2F0X2x2bDI9fmFueX4mcF9wYWdIPTE*\&p_li=(last updated Nov.4, 2003) (on file with the Indiana Health Law Review).

169. JCAHO has developed different standards for each type of health care organization it accredits including ambulatory care providers, assisted living providers, behavioral health care providers, critical access hospitals, health care networks, home care providers, hospitals, laboratory service providers, long-term care providers, and office-based surgery practices. For more information regarding the organizations JCAHO accredits and JCAHO's accreditation standards, see Joint Comm. on Accreditation of Healthcare Orgs., For Accredited Organizations, at http://www.jcaho.org/accredited+organizations/index.htm (last visited Apr. 21, 2005) (on file with the Indiana Health Law Review).

170. CMS has codified its Conditions of Participation for Hospitals at 42 C.F.R. Part 482.

171. JOINT COMMISSION ON ACCREDITATION OF HEALTHCARE ORGANIZATIONS, HOSPITAL ACCREDITATION STANDARDS RI.2.10(2) (2004) [hereinafter JCAHO STANDARDS].

172. Id. at RI.2.10(4).

173. Id. at Rationale for PC.8.70. JCAHO specifically identifies those elements that must be addressed in a hospital's spiritual assessment:

Spiritual assessment should, at a minimum, determine the patient's denomination, beliefs, and what spiritual practices are important to the patient. This information would assist in determining the impact of spirituality, if any, on the care/services being provided and will identify if any further assessment is needed. The standards require organizations to define the content and scope of spiritual and other assessments and the qualifications of the individual(s) performing the assessment. 
Many state laws also require hospitals to respect patients' spiritual values. For example, the regulations implementing the Texas Hospital Licensing Law require Texas hospitals to "acknowledg[e] the psychosocial and spiritual concerns of the patient and the family regarding dying and the expression of grief by the patient and family." 174 The same regulations explain that, "the care of the patient includes consideration of the psychosocial, spiritual, ${ }^{175}$ and cultural variables that influence the perceptions of illness."176

If a state or federal law requires a covered entity, or a workforce member thereof, to use or disclose PHI, the Privacy Rule also permits the use or disclosure. ${ }^{177}$ One could argue that because accreditation standards and state regulations require hospital chaplains to address the spiritual needs of their patients,

Examples of elements that could be but are not required in a spiritual assessment include the following questions directed to the patient or his/her family:

Who or what provides the patient with strength and hope?

Does the patient use prayer in their life?

How does the patient express their spirituality?

How would the patient describe their philosophy of life?

What type of spiritual/religious support does the patient desire?

What is the name of the patient's clergy, ministers, chaplains, pastor, rabbi?

What does suffering mean to the patient?

What does dying mean to the patient?

What are the patient's spiritual goals?

Is there a role of church/synagogue in the patient's life?

How does your faith help the patient cope with illness?

How does the patient keep going day after day?

What helps the patient get through this health care experience?

How has illness affected the patient and his/her family?

Joint Commission on Accreditation of Health Care Organizations, Long Term Care: Spiritual Assessment, at http://www.jcaho.org/accredited+organizations/long+term+care/ standards/faqs/provision+of+care/assessment/spiritual+assessment.htm. (last revised Jan. 1, 2004) (on file with the Indiana Health Law Review).

174. 25 TEX. ADMIN. CODE $§ 133.42$ (a)(I)(B)(ii)(III) (West 2005).

175. Both the JCAHO standards as well as the regulations implementing the Texas Hospital Licensing Law use the term spiritual, but neither JCAHO nor the Texas Department of State Health Services define the term. However, a 2001 white paper adopted by The Association for Clinical Pastoral Education, The Association of Professional Chaplains, The National Association of Catholic Chaplains, and The National Association of Jewish Chaplains, explain that the word spirituality "describes an awareness of relationships with all creation, an appreciation of presence and purpose that includes a sense of meaning." PROFESSIONAL CHAPLAINCY, supra note 1 , at 2 . The white paper further explains that the term spirituality is broader than the term religion and that spirituality includes religion and that spiritual care includes pastoral care. Id.; see also KOENIG ET AL., supra note 2, at 17-23 (discussing the definitions of spirituality and religion); Paul S. Mueller et al., Religious Involvement, Spirituality, and Medicine: Implications for Clinical Practice, 76 MAYO CLINIC Proc. 1225 (2001) (explaining that religion refers to participation in organized religion whereas spirituality refers to participation in personal processes, such as an individual's quest for meaning, purpose, or transcendence); Burton \& Bosek, supra note 1, at 98 (discussing the difference between religion and spirituality).

176. 25 TEX. ADMIN. CODE $\S 133.42(a)(1)(B)(i)$.

177. 45 C.F.R. $\$ 164.512$ (a)(1) (2005) (“A covered entity may use or disclose protected health information to the extent that such use or disclosure is required by law and the use or disclosure complies with and is limited to the relevant requirements of such law"). 
and because hospital chaplains need access to PHI to address these needs, ${ }^{178}$ then the Privacy Rule would permit such access. ${ }^{179}$

\section{Religion is an Epidemiologically Protective Factor}

Numerous published studies, meta-analyses, systematic reviews, and subject reviews examining the association between religion or spirituality and health outcomes find that religious involvement and spirituality are associated with better health outcomes, including greater longevity, coping skills, and health-related quality of life, as well as less anxiety, depression, and suicide. ${ }^{180}$ A discussion of all of the literature and studies linking religion and spirituality to better health outcomes ${ }^{181}$ is beyond the scope of this Article. However, one

178. As discussed in the text accompanying note 156, supra, hospital chaplains who have access only to directory information still can identify and locate patients within the hospital. However, many of the chaplains' other job duties, such as participating in ethics committees, hospital rounds, and patient care meetings, would be severely restricted or prohibited.

179. 45 C.F.R. $\S 164.512(\mathrm{a})(1)$.

180. See Levin et al., supra note 2; Mueller et al., supra note 175 , at 1225 . The fourth edition of the Diagnostic and Statistical Manual of Mental Disorders also recognizes religion and spirituality as relevant sources of emotional support (and distress). AMERICAN Psychiatric Association, Diagnostic and Statistical MaNUAL OF MENTAL Disorders 685 (4th ed., 1994).

181. See, e.g., Mueller et al., supra note 175 , at 1226 (noting that "a majority of the nearly 350 studies of physical health and 850 studies of mental health that have used religious and spiritual values have found that religious involvement and spirituality are associated with better health outcomes."); Sloan et al., supra note 2, at 664-67 (discussing the empirical evidence relating religion and health outcomes); Paul Alexander Clark et al., supra note 2, at 659 (stating that "The Joint Commission on Accreditation of Healthcare Organizations (JCAHO) has acknowledged that patients' 'psychosocial, spiritual, and cultural values affect how they respond to their care' .... " and that "Data analysis revealed a strong relationship between the 'degree to which staff addressed emotional/spiritual needs' and overall patient satisfaction.”). For discussions of the relationship between religion or spirituality and health, see generally LARRY DOSSEY, HEALING WORDS: THE POWER OF PRAYER AND THE PRACTICE OF MEDICINE 161-230 (1993); KOENIG ET AL., supra note 2, at 53-381 and 513-589; PASTOR AND PATIENT: A HANDBOOK FOR CLERGY WHO VISIT THE SICK (Richard Dayringer ed., 1982); THE SPIRITUAL Challenge of Health CARE (Mark Cobb \& Vanessa Robshaw eds., 1998); A. Gray, The Spiritual Component of Palliative Care, 8 PALLIATIVE MED. 215 (1994); Martha Ellen F. Highfield, Providing Spiritual Care to Patients with Cancer, 4 ClinICAL J. ONCOLOGY NURSING 115 (2000); Jeffrey S. Levin \& Linda M. Chatters, Research on Religion and Mental Health: An Overview of Empirical Findings, in HANDBOOK OF RELIGION AND MENTAL HEALTH 33, 33-50 (Harold G. Koenig ed., 1998); Jacqueline R. Mickley et al., Spiritual Well-Being, Religiousness and Hope Among Women with Breast Cancer, 24 IMAGE J. NURSING SCHOLARSHIP. 267 (1992); William R. Miller \& Carl E. Thoresen, Spirituality, Religion, and Health: An Emerging Research Field, 58 AM. PSYCHOLOGIST 24 (2003); William R. Miller \& Carl E. Thoreson, Spirituality and Health, in INTEGRATING SPIRITUALITY INTO TREATMENT 3-18 (William R. Miller ed., 1999); Mueller et al., supra note 175, at 1225; Johanna J. Mytko \& Sara J. Knight, Body, Mind and Spirit: Towards the Integration of Religiosity and Spirituality in Cancer Quality of Life Research, 8 PsYCHO-ONCOLOGY 439 (1999); T.A. Peri, Promoting Spirituality in Persons with Acquired Immunodeficiency Syndrome: A Nursing Intervention, 10 HOLISTIC NURSING PRAC. 68 (1995); C.M. Puchalski \& D.B. Larson, Developing Curricula in Spirituality and Medicine, 73 ACADEMIC MED. 970 (1998); L. Ross, The Spiritual Dimension: 
could rely on these studies to argue that: (1) religion and spirituality are epidemiologically protective factors; and, therefore (2) the provision of religious and spiritual services by hospital chaplains constitutes health care under the Privacy Rule.

\section{The Medicare Program Recognizes that Pastoral Care Has a "Beneficial and Therapeutic Effect" on Patients' Medical Conditions}

Although the Medicare Program does not directly pay hospitals for the costs of the pastoral care and other services provided to hospital patients by hospital chaplains, hospitals historically have been permitted to include such costs in their administrative and general ("A\&G") cost centers. ${ }^{182}$ Effective March 13, 2001, the federal Centers for Medicare and Medicaid Services ("CMS") adopted a regulation specifically permitting hospitals to claim the reasonable costs associated with the provision of clinical pastoral education, which include the costs associated with providing a minimum of one year (or 1200 hours) of supervised clinical experience required for chaplain who wishes to become board certified. ${ }^{183}$ In a regulatory provision establishing the methodology for paying for the costs of "approved nursing and allied health education activities," CMS explained that activities accredited by the Association for Clinical Pastoral Education ("ACPE") would constitute an approved program:

Approved nursing and allied health education programs. CMS will consider an activity an approved nursing and allied health education program if the program is a planned program of study that is licensed by State law, or if licensing is not required, is accredited by the recognized national professional organization for the particular activity. Such national accrediting bodies include, but are not limited to, the Commission on Accreditation of Allied Health Education Programs, the National League of Nursing Accrediting Commission, the Association for Clinical Pastoral Education Inc., and the American Dietetic Association. ${ }^{184}$

Interestingly, a member of the public voiced his disagreement with the inclusion of clinical education as an approved program for Medicare payment,

its Importance to Patients' Health, Well-Being and Quality of Life and Its Implications for Nursing Practice, 32 INT. J. NuRSING STUD. 457 (1995); J. Walton, Spiritual Relationships: $A$ Concept Analysis, 14 J. HolistiC NURSING 237 (1996).

182. Medicare Program; Payment for Nursing and Allied Health Education, 66 Fed. Reg. 3358, 3366 (Jan. 12, 2001).

183. See id. at 3358 (noting an effective date of March 13, 2001).

184. 42 C.F.R. $\S 413.85(\mathrm{e})$ (2005) (emphasis added). 
arguing that: (1) such a policy would violate the requirement for separation of church and state; and (2) pastoral counseling does not qualify as direct patient care because Medicare does not pay directly for the care provided by pastoral counselors. ${ }^{185}$ However, CMS responded to the comment on January 12, 2001, by explaining that, "[a]s early as the mid-1970s, Medicare recognized pastoral care as having a beneficial and therapeutic effect on the medical condition of a patient, and, therefore, the costs a provider incurs to furnish such care to its patients are considered patient care related costs."186

In addition, CMS published its final changes to the hospital inpatient prospective payment systems and fiscal year 2004 rates on August 1, 2003. ${ }^{187}$ In that publication, CMS concluded that hospitals are not eligible to receive reimbursement for the reasonable costs of: (1) CPE internships (or any other CPE training that is a requirement for a degree, whether undergraduate, graduate, or doctoral); (2) second year CPE residencies, or any CPE beyond 1600 hours; and (3) supervisory CPE. However, CMS also concluded that hospitals are eligible to receive reimbursement for the reasonable costs of operating the first year of CPE residencies that consist of 1600 hours of training and that lead to board certification in chaplaincy. ${ }^{188}$

In summary, the Medicare Program continues to view pastoral care as having a beneficial and therapeutic effect on patients' medical conditions and continues to allow hospitals to include costs relating to most first year CPE residencies in their $A \& G$ cost centers. Accordingly, an argument exists that hospital chaplains who have completed a one-year CPE residency for board certification are like other allied health professionals whose services are viewed as health care under the Privacy Rule.

\section{Hospital Chaplains Do Not Inappropriately Use or Disclose PHI}

A final argument requires a return to the reason HHS adopted the Privacy Rule in the first place. Privacy breaches that caught HHS' attention included cases in which: (1) a Michigan-based health system accidentally posted the medical records of thousands of patients on the Internet; (2) a Utahbased pharmaceutical benefits management firm used patient data to solicit business for its owner, a drug store; (3) an employee of the Tampa, Florida, health department took a computer disk containing the names of 4000 people who had tested positive for HIV; (4) the health insurance claims forms of thousands of patients blew out of a truck on its way to a recycling center in East Hartford, Connecticut; (5) a patient in a Boston-area hospital discovered that her medical record had been read by more than 200 of the hospital's

185. Medicare Program; Payment for Nursing and Allied Health Education, 66 Fed. Reg. at 3366 .

186. $I d$.

187. Medicare Program; Changes to the Hospital Inpatient Prospective Payment Systems and Fiscal Year 2004 Rates, 68 Fed. Reg. 45,346, 45,668 (Aug. 1, 2003).

188. Id. at 45,426-27. 
employees; (6) a Nevada woman who purchased a used computer discovered that the computer still contained the prescription records of the customers of the pharmacy that had previously owned the computer (the pharmacy data base included names, addresses, social security numbers, and a list of all the medicines the customers had purchased); (7) a speculator bid $\$ 4000$ for the patient records of a family practice in South Carolina and attempted to sell the purchased records back to the former patients; (8) Johnson and Johnson reportedly marketed a list of five million names and addresses of elderly incontinent women without their permission; and (9) a few weeks after an Orlando woman had her doctor perform some routine tests, she received a letter from a drug company promoting a treatment for her high cholesterol. ${ }^{189}$ Neither the preamble to the Privacy Rule nor case law research identified one reported case in which a hospital chaplain was alleged to have inappropriately used or disclosed a patient's PHI. ${ }^{190}$ Thus, one could argue that the privacy breaches that prompted HHS to adopt the Privacy Rule did not occur in the context of hospital chaplaincy and that limiting chaplains' access to PHI will not reduce an already low risk of inappropriate health information management.

\section{CONCLUSION}

The preamble to the federal Department of Health and Human Services' Privacy Rule is, perhaps, the latest chapter in the history of the continually evolving relationship between American medicine and religion. Over the last four centuries, the medical and religious establishments in the United States have engaged in action and reaction, participation and withdrawal, and competition and cooperation with respect to their professional domains. Depending on when asked, one might have described American medicine and religion as incompatible, complimentary, or even augmentative, or as enemies or allies. By outlining an almost exclusive role for medicine in the provision of health care and related social and support services and attempting to limit religious

189. Standards for Privacy of Individually Identifiable Health Information, 65 Fed. Reg. $82,462,82,467$ (Dec. 28, 2000).

190. Chaplains may have a heightened understanding of the necessity of maintaining the confidentiality of information revealed to them in light of state statutory provisions that typically establish privileges for persons who communicate with members of the clergy and that permit such persons to prevent clergy from disclosing confidential communications. For example, the Texas Rules of Evidence states that, "[a] person has a privilege to refuse to disclose and to prevent another from disclosing a confidential communication by the person to a member of the clergy in the member's professional character as spiritual adviser." TEX. R. EVID. 505(b). See generally James J. Gill \& Dana L. Farnsworth, Confidentiality, in PSYCHIATRY, THE ClERGY AND PASTORAL COUNSELING: THE ST. JOHN's STORY 313, 313-22 (Dana L. Farnsworth \& Francis J. Braceland eds., 1969) (discussing the need for confidentiality in the context of pastoral counseling). 
practitioners to the role of just visiting the sick, ${ }^{191}$ religion is not currently viewed, at least by HHS in its Privacy Rule, as complimentary or augmentative of medicine.

Regardless of their legislatively or regulatively prescribed domains, ${ }^{192}$ religion and medicine share many common purposes, functions, and actions. ${ }^{193}$ Many scholars of religion and medicine have concluded that religion cannot possibly be divorced from medicine. ${ }^{194}$ Thus, one might ask why HHS felt the need to exclude "methods of healing that are solely spiritual" and "solely religious healing" from the definition of health care. Perhaps one explanation lies in the changing health care environment. In an era of managed care, where every cost is scrutinized and every benefit carefully assessed, chaplains must justify their presence in modern hospitals. ${ }^{195}$ Many hospital chaplains are expected to demonstrate a measurable impact of their services in terms of speed recovery, improved outcomes, and increased patient satisfaction, and to show that their services either will save money or increase hospital revenue. ${ }^{196}$

Unfortunately, many clinically-oriented hospital chaplain programs have neither the time nor the resources to: (1) document existing relationships between religious involvement and health outcomes relating to depression, prevention, and speed of recovery, among other outcomes; or (2) conduct additional research showing a positive relationship between pastoral care and better health outcomes. Managed care organizations thus place hospital chaplains in a tricky position by asking them to justify their existence. ${ }^{197}$ Chaplains that fail to demonstrate and document a positive effect of their services on patient outcomes may be released or replaced by contract or parttime chaplains. For example, on October 31, 1991, the Georgia Legislature decided to make up a $\$ 415$ million budget deficit by eliminating all of the fulltime clinical chaplain positions in its state-operated facilities. ${ }^{198}$

The changing health care environment may not be the only reason why HHS excluded "methods of healing that are solely spiritual" and "solely religious healing" from the definition of health care. Perhaps the physicians and other members of the medical establishment who submitted comments to

191. See, e.g., PASTOR AND PATIENT: A HANDboOK FOR CleRgy Who Visit THE Sick (Richard Dayringer ed., 1982) (the title speaks for itself); Vanderpool, supra note 165, at 255 ("A very common, although not necessary accurate, image of the relationship between religion and medicine is the image of a chaplain visiting a large hospital.").

192. Harold Y. Vanderpool \& Jeffrey S. Levin, Religion and Medicine: How Are They Related?, 29 J. RELIGION \& HEALTH 9, 14 (1990) ("Over time, humans have, of course, defined distinctive roles for the domains of religion and medicine; yet much sharing and competing remains.").

193. Id. at 9 (discussing the shared purposes, functions, and actions of religion and medicine).

194. Foster, supra note 36, at 249.

195. KOENIG ET AL., supra note 2, at 450.

196. Id.

197. Id. at $450-51$.

198. Id. 
HHS regarding the 1999 Proposed Privacy Rule and the 2002 Proposed Modifications were concerned about hospital chaplains and other religious practitioners encroaching on their professional domains. On the other hand, perhaps HHS simply was unaware of the special training, the unique role, and the diverse job functions of today's hospital chaplain.

Regardless of the reason for its preamble, HHS needs to clarify whether hospital chaplains have access to PHI beyond directory information. Three potential approaches for HHS to consider include an opt-out approach, an optin approach, or a do-nothing approach.

\section{A. An Opt-Out Approach}

One approach is for HHS to amend the Privacy Rule to align religious and spiritual services with treatment, payment, and health care operations activities. Currently, 45 C.F.R. $\S 164.506$ allows covered entities to use and disclose PHI for treatment, payment, and health care operations activities without the prior written authorization of the individual who is the subject of the information. ${ }^{199}$ HHS could consider adding a new paragraph (d) to 45 C.F.R. $\S 164.506$ to give hospital chaplains access to PHI as necessary to carry out their duties and to address patients' spiritual needs in accordance with JCAHO standards and state law, as appropriate. Although hospital chaplains and professional chaplain associations are in the best position to propose language that would accomplish this goal, one formulation is:

(d) Implementation specifications: Religious and spiritual activities; other support services. Hospital chaplains may use or disclose protected health information to provide religious, spiritual, and related support services as required to address the spiritual needs of patients in accordance with the applicable standards of the Joint Commission on Accreditation of Healthcare Organizations and the requirements of applicable state law.

HHS, hospital chaplains, and professional chaplain associations could work together to define those activities that constitute religious and spiritual activities for purposes of the amendment.

Currently, the Privacy Rule allows individuals to request covered entities for greater privacy protections under 45 C.F.R. $\S 164.522$. For example, if a patient does not want his or her PHI used for treatment, payment, or health care operations activities, the patient is permitted to request the covered entity to restrict uses and disclosures for such activities ${ }^{200}$ although the covered entity 
is not required to agree to the request. ${ }^{201}$ To accommodate patients who do not want hospital chaplains to use their PHI, HHS could further amend 45 C.F.R. $\S 164.522$ to add a new paragraph (a)(1)(i)(C), which would permit patients to request restrictions relating to:

(C) Uses or disclosures of protected health information permitted under $\S 164.506(d)$.

Finally, HHS could amend 45 C.F.R. $§ 164.522(a)(1)(i i)$ to provide that:

(ii) A covered entity is not required to agree to a restriction under paragraphs (a)(1)(i)(A) and (B) of this section. A covered entity is required to agree to a restriction under paragraph $(a)(1)(i)(C)$ of this section.

These amendments offer one attempt to balance the religious and spiritual needs of some patients and the requirements for hospitals to address patients' spiritual care with the rights of patients not to receive religious and spiritual care. One possible critique is that this approach implicates the Establishment Clause of the First Amendment, which prohibits laws "respecting an establishment of religion." 202 This critique might stem from the incorrect belief that hospital chaplains are allowed to proselytize with respect to a particular faith tradition. ${ }^{203}$ In determining whether the amendments would violate the Establishment Clause, a court would analyze whether the amendments have a bona fide secular purpose and whether their primary effect is to advance or inhibit religion. $^{204}$ After speculating whether the provision in the Privacy Rule allowing covered entities to disclose directory information to community clergypersons $^{205}$ violated the Establishment Clause, HHS concluded that that the provision exists "as an accommodation to patients who seek to engage in religious conduct" and that it "avoids a government-imposed restriction on the disclosure of information that could disproportionately affect the practice of religion." described in this Part IV.A only seek to accommodate patients who want religious or spiritual care and that the proposal requiring covered entities to

201. Id. §164.522(a)(1)(ii).

202. U.S. CONST. amend. I.

203. PROFESSIONAL CHAPLAINCY, supra note 1, at 8 ("Professional chaplains reach across faith group boundaries and do not proselytize.").

204. Lemon v. Kurtzman, 403 U.S. 602, 612-13 (1971); see Agostini v. Felton, 521 U.S. 203 (1997); County of Allegheny v. ACLU, 492 U.S. 573 (1989).

205. 45 C.F.R. § 164.510(a)(1)(ii)(A) (2005).

206. Standards for Privacy of Individually Identifiable Health Information, 65 Fed. Reg. $82,462,82,522$ (Dec. 28, 2000) ("The privacy regulation passes this test because its purpose is to protect the privacy of individuals - regardless of their religious affiliation - and it does not cause excessive government entanglement."). 
adhere to patient requests to opt out of receiving religious and spiritual care will ensure that no religion is advanced.

\section{B. An Opt-In Approach}

A second approach is to amend the Privacy Rule to allow hospital chaplains to access PHI only if a patient "opts in" to religious or spiritual care, assessment, or counseling through an in-person interview or a written document provided to the patient at the time of registration or admission. Under this approach, the chaplain would be limited to using directory information about the patient if the patient did not opt in. To formulate this approach, HHS could consider adding a new paragraph (c) to 45 C.F.R. $§ 164.510$, as follows:

(c) Standard: uses for religious and spiritual activities and related support services. A hospital chaplain may use a patient's protected health information to provide religious and spiritual activities and related support services if the patient agrees orally or in writing to such use. The covered entity shall document the patient's agreement in the medical record.

As with the opt-out approach, HHS, hospital chaplains, and professional chaplain associations could work together to define those activities that constitute religious and spiritual activities and related support services.

In attempting to balance the religious and spiritual needs of some patients with the rights of other patients not to receive religious or spiritual care, this approach gives greater weight to the rights of patients not to receive religious or spiritual care. This approach has the benefit of not raising any issues under the Establishment Clause because the hospital chaplain would only be providing religious or spiritual services to a patient if the patient specifically requested or agreed to the use of his or her information for such services. However, this approach potentially runs afoul of state laws and JCAHO standards that require hospitals to address the religious and spiritual needs of patients. This approach also would interfere with or completely eliminate the ability of chaplains to perform many of the other job functions described in Part II.D of this Article. Moreover, this approach places the burden on patients who did not opt in to religious and spiritual care but who later change their minds to specifically request such services. Finally, this approach would require significant changes to the policies and practices of many hospitals that currently allow chaplains full access to the PHI of inpatients.

\section{The Do-Nothing Approach}

A third approach is for HHS to leave the Privacy Rule as is. HHS would benefit from the do-nothing approach because it would avoid the lengthy 
notice and comment rulemaking process required to amend the Privacy Rule. ${ }^{207}$ However, health care attorneys and hospital chaplains would continue to debate the interpretation of the preamble language excluding "methods of healing that are solely spiritual" and "solely religious services" from the definition of health care. ${ }^{208}$

Regardless of whether HHS adopts an opt-out approach, an opt-in approach, or a do-nothing approach, its action (or omission) will add a new chapter to the history of religion and medicine.

207. HHS still could adopt an official position and avoid the notice and comment rulemaking process by issuing a new "guidance" document or publishing a new response to a frequently-asked-question. See supra notes 167 and 168.

208. See supra text accompanying notes $4,5,6$, and 7 . 